\title{
Analysis of Sensitive Parameters Affecting Unlocking Force of Finger Lock in Landing Gear
}

\author{
Yu Hou $\mathbb{D}^{1},{ }^{1}$ Ming Zhang, ${ }^{1}$ and Hong Nie $\mathbb{D}^{2}$ \\ ${ }^{1}$ State Key Laboratory of Mechanics and Control of Mechanical Structures, Nanjing University of Aeronautics and Astronautics, \\ Nanjing, Jiangsu, China \\ ${ }^{2}$ Key Laboratory of Fundamental Science for National Defense-Advanced Design Technology of Flight Vehicle, Nanjing University of \\ Aeronautics and Astronautics, Nanjing, Jiangsu, China
}

Correspondence should be addressed to Hong Nie; hnie@nuaa.edu.cn

Received 16 November 2020; Revised 15 December 2020; Accepted 2 January 2021; Published 13 January 2021

Academic Editor: Jacopo Serafini

Copyright (C) 2021 Yu Hou et al. This is an open access article distributed under the Creative Commons Attribution License, which permits unrestricted use, distribution, and reproduction in any medium, provided the original work is properly cited.

\begin{abstract}
The mechanical characteristics of the unlocking force of the landing gear finger lock were studied in this paper, the influence of its diameter, fingertip angle, wear, and other factors on the unlocking force in one complete working cycle was analyzed, and the sensitive parameters that affect the unlocking force were obtained. Firstly, the unlocking force and wear of finger lock were calculated theoretically, and the changing rule of the unlocking force and wear with each parameter was obtained. Then, the validity of the correlation coefficient and model was verified by experiment. Finally, combined with the effective coefficient obtained from the experiment, the Archard wear model was used to simulate the change rule of lock force. The results show that in one complete working cycle, the inner surface diameter is negatively related to the unlocking force, fingertip diameter has little effect on the unlocking force, fingertip angle is negatively related to the unlocking force, and wear is positively related to the unlocking force; friction coefficient and fingertip angle are high sensitive parameters that affect the unlocking force, which have obvious effect on the unlocking force. The inner surface diameter, fingertip diameter of finger lock, and wear are the low sensitive parameters that affect the unlocking force, and the influence on the unlocking force is weak.
\end{abstract}

\section{Introduction}

The landing gear is an important mechanism for aircraft taking off and landing. When the landing gear is retracted and released, the locking mechanism [1] will complete locking to realize the landing gear fixation, so that the aircraft can take off and land safely. Therefore, whether the landing gear lock mechanism can work normally is directly related to the safety of the aircraft [2], which is an important part of the landing gear design. During the use of the landing gear, the lock mechanism will gradually wear during the unlocking and locking process, resulting in the change of unlocking force [3]. If the unlocking force is abnormal, it will lead to the landing gear retraction failure, which will threaten the safety of aircraft takeoff and landing $[4,5]$.

Many researches have been done on the parameter design of the landing gear at both national and international levels [6-8]. For example, the landing mechanical properties of the landing gear with fixed design parameters were studied [9]. The sensitivity factors of the landing gear were studied, and the design parameters of the landing gear were optimized [10]. There are also many theories about wear problem [11]. Wear is a kind of phenomenon in contact. Hertz [12] contact and Coulomb [13] friction theorem in contact theory are often used to calculate friction. There are many different theoretical models for wear calculation. For example, Archard used the Archard model to study the effect of wear on the dynamic performance of mechanisms under complex working conditions [14]. Nowotyńska and Kut calculated the wear using the energy density method and obtained the wear result of the finger lock [15]. Rupert and Schuh used the Archard model to calculate the wear [16]. Alroqi and Wang used the Archard model to study the wear of aircraft tires [17]. Ying et al. studied the Archard model for a certain type of aircraft joint [18]. Wang et al. used the integrated wear rate equations of Usui, Takeyama, and Attanasio to study the tool wear [19]. 


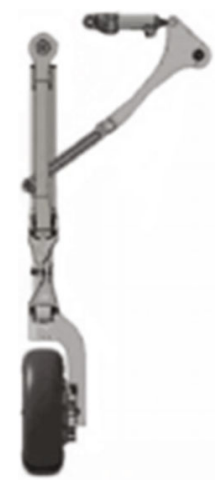

(a) Locked status

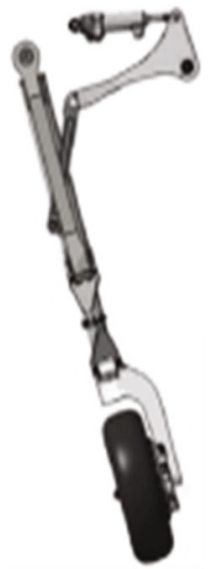

(b) Unlocked status

Figure 1: Working status of locking mechanism.

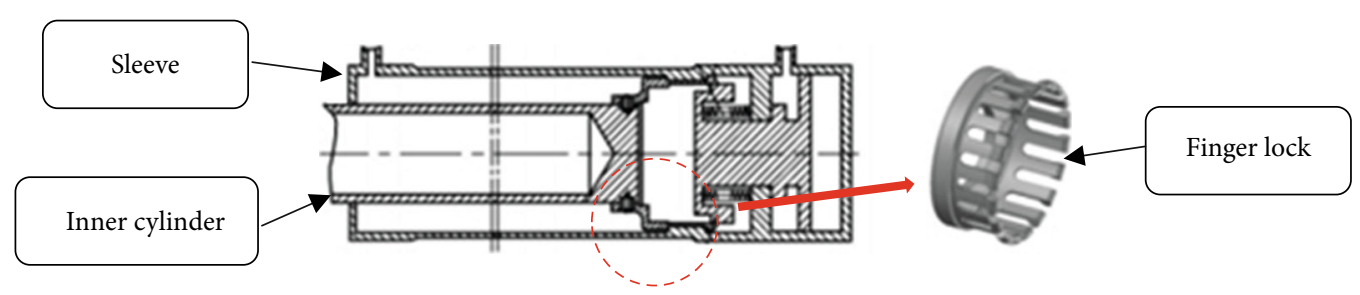

Figure 2: Assembly drawing of the finger lock.

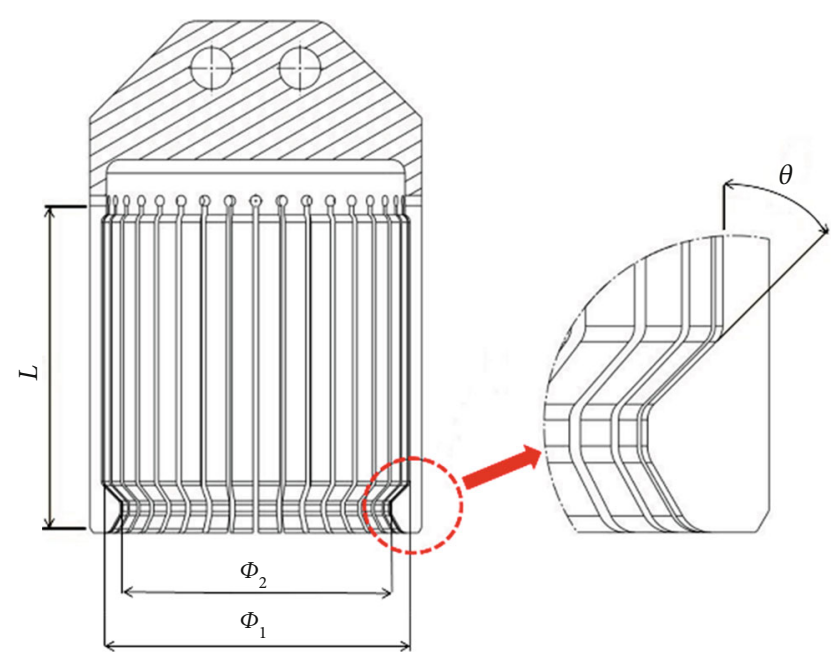

Figure 3: Main parameters of the finger lock.

Wang et al. used the latest artificial neural network method to study the wear problem [20].

In the actual use process, it can be found that the unlocking force of the finger lock will change in a complete working cycle (500 unlocking cycles), which has an impact on the stability of the landing gear retraction and release, and even occurs jamming in serious cases. Therefore, it is necessary to study the sensitivity of each design parameter to the influence of unlocking force and the change rule of unlocking force. In this paper, the influence of different parameters on the unlocking force in a complete working cycle (500 unlocking cycles) of the landing gear was studied. The mechanical characteristics of the unlocking process of finger lock were analyzed theoretically. Then, through the experiment, the real landing gear retraction and release process of the finger lock unlocking process was simulated, and the theoretical calculation of the relevant parameters was verified. Finally, an effective finite element model was established, and the sensitivity of each parameter to the unlocking force was obtained.

\section{Mechanical Model of Finger Lock}

2.1. Finger Lock Introduction. The landing gear is folded or unfolded when the aircraft takes off or lands. In order to make the aircraft safe, it is necessary to use the locking mechanism to lock the retractable landing gear. The lower lock is often used in the folding landing gear. When the landing gear changes from the folded state to the unfolded state before landing, the lower lock is needed to lock the landing gear to maintain its stable unfolded state. The typical working state of the locking mechanism is shown in Figure 1.

Finger lock is a kind of lower lock, which is stable and reliable and can bear large load. This type of lock mechanism is shown in Figure 2. The unlocking and locking process of the finger lock needs to be completed with the assistance of relevant auxiliary mechanisms $[21,22]$.

The main design parameters of the finger lock studied in this paper are shown in Figure 3. As shown in Figure 3, the 


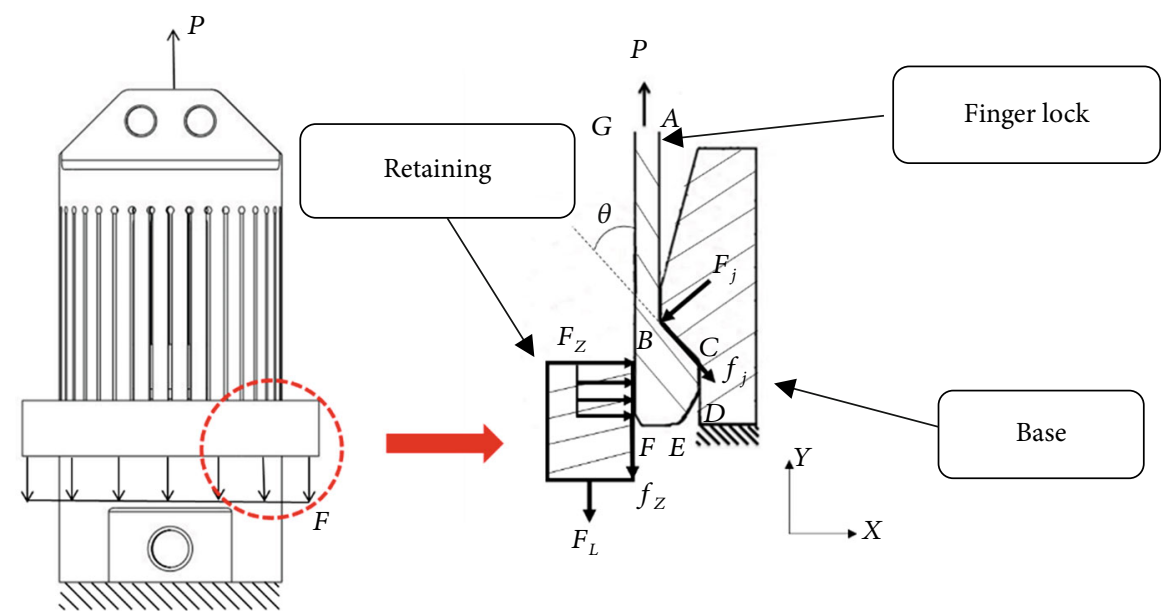

(a) Overall model

(b) Partial model

Figure 4: The finger lock unlocking force. (a) Overall model. (b) Partial model.

TABLE 1: Related geometric parameters.

\begin{tabular}{lc}
\hline Geometric parameter & Value \\
\hline$\Phi(\mathrm{mm})$ & 180.0 \\
$\Phi_{1}(\mathrm{~mm})$ & 111.6 \\
$\Phi_{2}(\mathrm{~mm})$ & 98.0 \\
$L_{C E y}(\mathrm{~mm})$ & 11.0 \\
$L_{B D x}(\mathrm{~mm})$ & 6.8 \\
$\theta$ & $45^{\circ}$ \\
\hline
\end{tabular}

bulge at the bottom of the finger lock matches the groove on the corresponding base. When they are in the locked position, the retaining ring will move to wrap the finger lock and lock the locking mechanism. The sensitive parameters are inner surface diameter $\Phi_{1}$, fingertip diameter $\Phi_{2}$, and fingertip angle $\theta$.

2.2. Mechanical Model of Finger Lock Unlocking Force. The force model of the type lock is shown in Figure 4. During the working process of the finger lock, the top of the finger lock is subject to tensile force $P$; the finger lock and base are in line contact at $B$, the finger lock is subject to normal pressure $F_{j}$ and tangential static friction $f_{j}$ at $B$; the finger lock and retaining ring are in face contact at $F$. Because the retaining ring moves down at a constant speed under the action of $F_{L}$ in the unlocking process, the finger lock is affected by the normal surface pressure $F_{Z}$ (contact area $S$ ) and the tangential dynamic friction $f_{Z}$ at $F$. The external forces of finger lock are $F_{j}, f_{j}, F_{Z} S, f_{Z}$, and $P$, where $P$ is the known preload. $F_{L}$ refers to the unlocking force of the type lock, which is equal to the tangential dynamic friction $f_{Z}$.

In the process of retaining ring falling at a constant speed, the finger lock is stationary. Therefore, the external force on the finger lock is balanced. The force balance equation and moment balance equation of the finger lock are as follows.
The force balance equation in $X$ direction is as follows:

$$
F_{Z} S+f_{j} \sin \theta=F_{j} \cos \theta .
$$

The force balance equation in $Y$ direction is as follows:

$$
P=F_{j} \sin \theta+f_{j} \cos \theta+f_{Z}
$$

Taking point $B$ as the center, the moment balance equation is as follows:

$$
\frac{P L_{A G x}}{2}=F_{Z} S L_{B F y}+f_{Z} L_{B F x}
$$

In Figure 4 the friction is dynamic friction at $F$, so the pressure and friction force equation can be obtained:

$$
f_{Z}=\mu F_{Z} S
$$

In Figure 4, observing the geometric parameters of the finger lock, it can be known that the angle $\theta$ between edge $B D$ and edge $A B$ is an independent variable; the width of edge $A G$ is an independent variable, and the length of edge $B D$ is an independent variable. The relationship between other known parameters and variables is as follows:

$$
\begin{aligned}
& L_{A G x}=\frac{\Phi-\Phi_{1}}{2}, \\
& L_{B F y}=L_{C E y}+L_{B D x} \tan \theta, \\
& L_{B F x}=L_{A G x} .
\end{aligned}
$$

In equations (5)-(7) and Table $1, L_{A G x}$ represents the length of edge $A G$ in $X$ direction, $L_{B F y}$ represents the length of point $B$ to point $F$ in $Y$ direction, $L_{C E y}$ represents the length of point $C$ to point $E$ in $Y$ direction, $L_{B D y}$ represents the length of point $B$ to point $D$ in $Y$ direction, $L_{B F x}$ represents the length of point $B$ to point $F$ in $X$ direction, and 


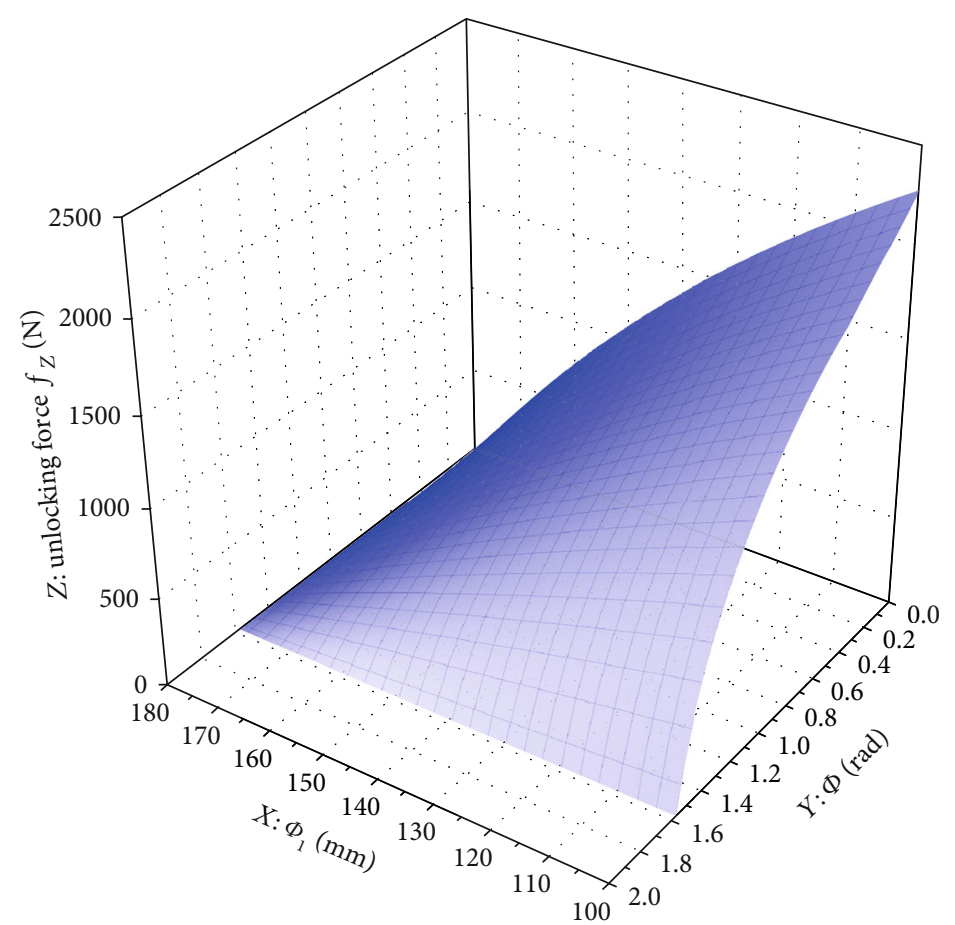

FIgURE 5: $f_{Z}, \Phi_{1}$, and $\theta$ relationship.

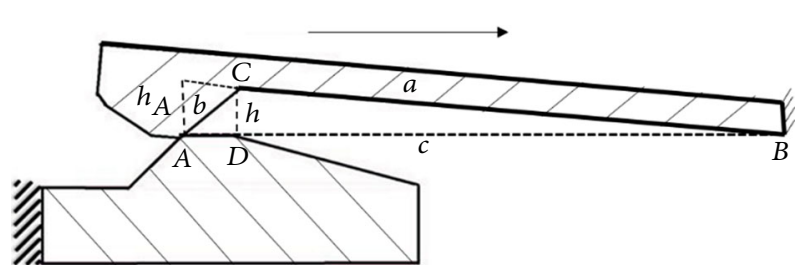

Figure 6: Force analysis of the finger lock in unlocking process.

$L_{B D x}$ represents the length of point $B$ to point $D$ in $X$ direction.

Finally, the unlocking force $f_{Z}$ can be obtained by solving equations (1)-(7):

$$
f_{z}=\frac{P\left(\Phi-\Phi_{1}\right)}{2\left(\left(\left(L_{C E y}+L_{B D x} \tan \theta\right) / \mu\right)+\Phi-\Phi_{1}\right)} .
$$

The relationship among $f_{Z}, \Phi_{1}$, and $\theta$ is shown in Figure 5, where $X$ axis is $\Phi_{1}$; $Y$ axis is $\theta$; and $Z$ axis is $f_{Z}$. According to Figure 5, when $\theta$ is in the range of $0^{\circ} \sim 90^{\circ}, f_{Z}$ decreases with the increase of $\theta$, so they are negatively correlated. When $\Phi_{1}$ within $100 \mathrm{~mm} \sim 180 \mathrm{~mm}, f_{Z}$ decreases with the increase of $\Phi_{1}$, so they are negatively correlated.

\subsection{Wear Prediction Model of Finger Lock}

2.3.1. Maximum Deflection of Finger Lock. After unlocking the retaining ring, the base is fixed and the finger lock is controlled to move upward for $40 \mathrm{~mm}$. This process is the landing gear unlocking process. In this process, the finger lock is opened by the base, and the single finger of the finger lock is in a pure bending state. In Figure 6, it refers to the geometric position of the maximum bending of the type lock in this process.

As shown in Figure 6, edge $A B$ is expressed as $c$, edge $B C$ is expressed as $a$, edge $A C$ is expressed as $b$, length of $C D$ is $h$, point $A$ is angle $\alpha$, point $B$ is angle $\beta$, and point $C$ is angle $\gamma$. The relationship between $\gamma$ and $\theta$ in Figure 4 is $\gamma+\theta=\pi$.

According to triangle geometry, sine theorem, and cosine theorem, it can be obtained as

$$
\begin{aligned}
& \cos \gamma=\frac{a^{2}+b^{2}-c^{2}}{2 a b}, \\
& \sin \alpha=\frac{h}{b}, \\
& \sin \beta=\frac{h}{a}, \\
& \frac{\sin \alpha}{a}=\frac{\sin \beta}{b}=\frac{\sin \gamma}{c} .
\end{aligned}
$$

The deflection at point $C$ can be obtained by solving equations (9)-(12):

$$
h=\frac{a^{2} \sin \gamma \cos \gamma+\sqrt{a^{2} c^{2} \sin ^{2} \gamma-a^{4} \sin ^{4} \gamma} .}{c} .
$$

In equation (13), $\gamma$ is

$$
\gamma=\pi-\theta
$$




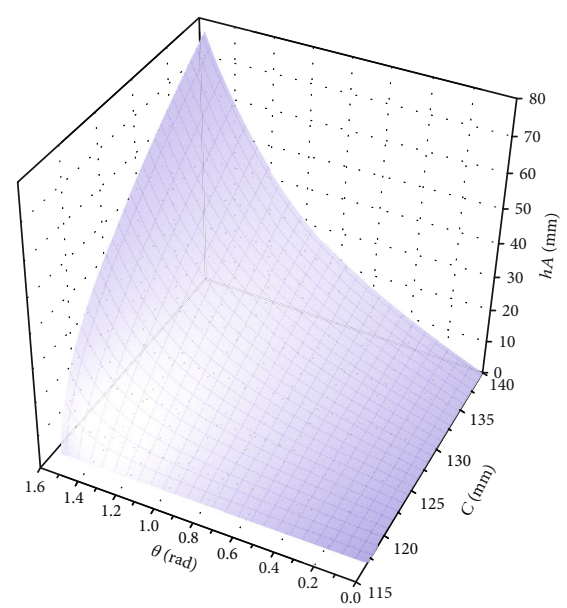

Figure 7: $h_{A}, c$, and $\theta$ relationship.

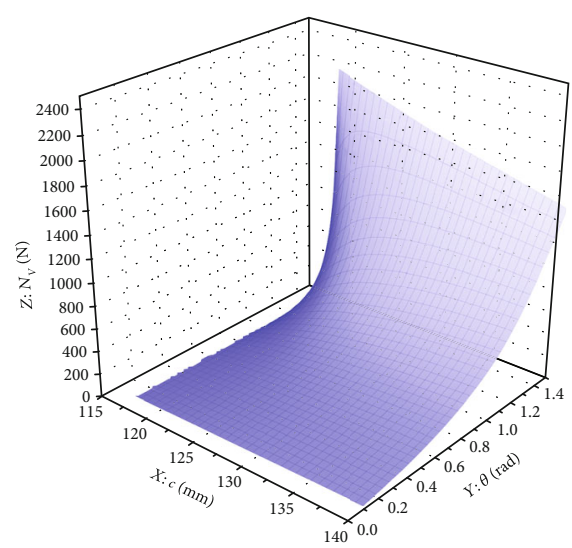

Figure 8: $N_{V}, c$, and $\theta$ relationship.

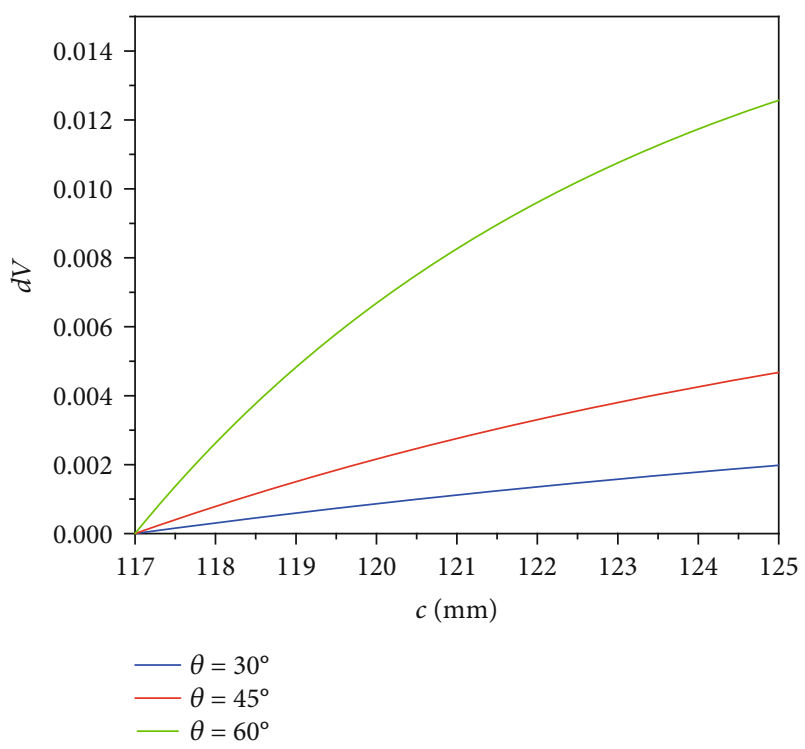

Figure 9: $d V$ at different angles.
According to the proportional relationship in Figure 6, the deflection at point $A$ can be obtained:

$$
\begin{aligned}
h_{A} & =\frac{c}{a} h=a \sin \gamma \cos \gamma+\sqrt{c^{2} \sin ^{2} \gamma-a^{2} \sin ^{4} \gamma} \\
& =\sqrt{c^{2} \sin ^{2} \theta-a^{2} \sin ^{4} \theta}-a \sin \theta \cos \theta .
\end{aligned}
$$

The relationship among $h_{A}, c$, and $\theta$ is shown in Figure 7 . It can be observed from Figure 7 that in the range of $117 \mathrm{~mm} \sim 140 \mathrm{~mm}, h_{A}$ increases with the increase of $c$, so they are positively related. In the range of $0^{\circ} \sim 90^{\circ}, h_{A}$ increases with the increase of $\theta$, so they are positively correlated.

2.3.2. Maximum Pressure of Finger Lock in Pure Bending. According to the deflection equation, pressure $N$ at point $A$ can be obtained:

$$
N=\frac{3 h_{A} E I}{c^{3}}
$$

Taking equation (15) into equation (16), pressure $N$ can be obtained:

$$
\begin{aligned}
N & =\frac{3\left(a \sin \gamma \cos \gamma+\sqrt{c^{2} \sin ^{2} \gamma-a^{2} \sin ^{4} \gamma}\right) E I}{c^{3}}, \\
& =\frac{3\left(\sqrt{c^{2} \sin ^{2} \theta-a^{2} \sin ^{4} \theta}-a \sin \theta \cos \theta\right) E I}{c^{3}} .
\end{aligned}
$$

According to Figure 6, total pressure $N$ is vertically downward. Therefore, pressure $N_{V}$ perpendicular to edge $A$ $C$ at point $A$ is

$$
N_{V}=\frac{N}{\cos \alpha}=\frac{3\left(\sqrt{c^{2} \sin ^{2} \theta-a^{2} \sin ^{4} \theta}-a \sin \theta \cos \theta\right) E I}{c^{3} \cos \alpha} .
$$

In equation (18), $\cos \alpha$ is

$\cos \alpha=\sqrt{1-\frac{h^{2}}{b^{2}}}=\sqrt{1-\left(\frac{\sqrt{a^{2} c^{2} \sin ^{2} \theta-a^{4} \sin ^{4} \theta}-a^{2} \sin \theta \cos \theta}{c \sqrt{c^{2}-a^{2} \sin ^{2} \theta}-c a \cos \theta}\right)^{2}}$.

The relationship between $N_{V}$ and $c$ and $\theta$ is shown in Figure 8 , where $X$ axis is $c, Y$ axis is $\theta$, and $Z$ axis is $N_{V}$. It can be observed from Figure 8 that within the value range of $117 \mathrm{~mm} \sim 140 \mathrm{~mm}, N_{V}$ increases with the increase of $c$, so their relationship is a positive correlation and the change rate is very small. In the range of $0^{\circ} \sim 90^{\circ}, N_{V}$ increases with the increase of $\theta$, so their relationship is a positive correlation and the change rate is large.

2.3.3. Wear Calculation Model of Finger Lock. The Archard wear calculation model is a commonly used wear theory model, which is based on the classical material elasticplastic deformation. According to this theory, the forms of wear can be divided into abrasive wear, corrosion wear, 


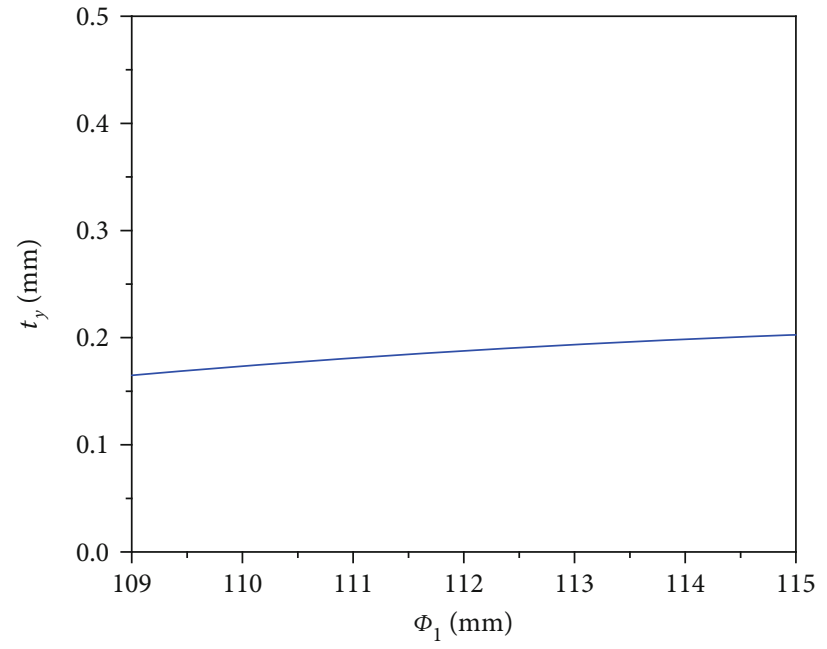

— Thickness of wear at $y$-axis

(a) $\Phi_{2}=98 \mathrm{~mm}, \theta=45^{\circ}$

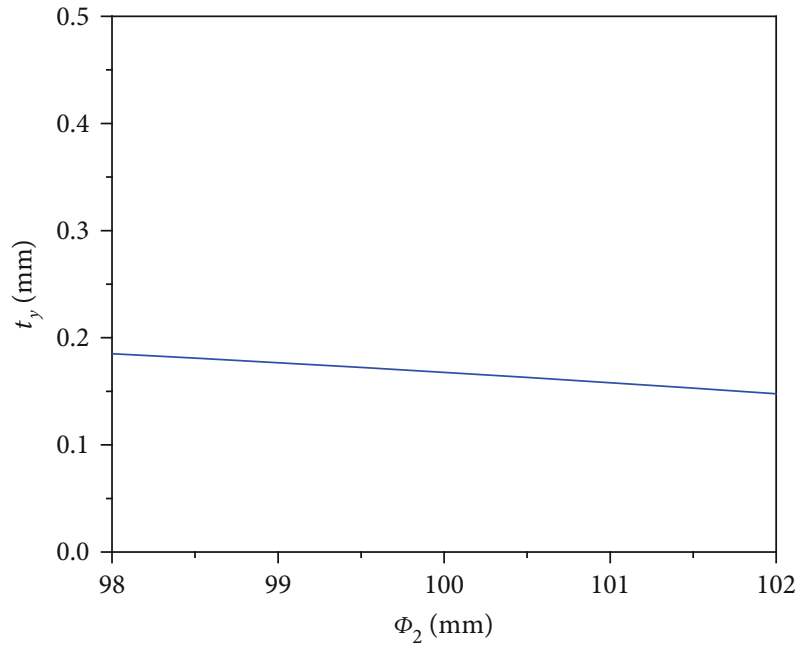

— Thickness of wear at $y$-axis

(b) $\Phi_{1}=111.6 \mathrm{~mm}, \theta=45^{\circ}$

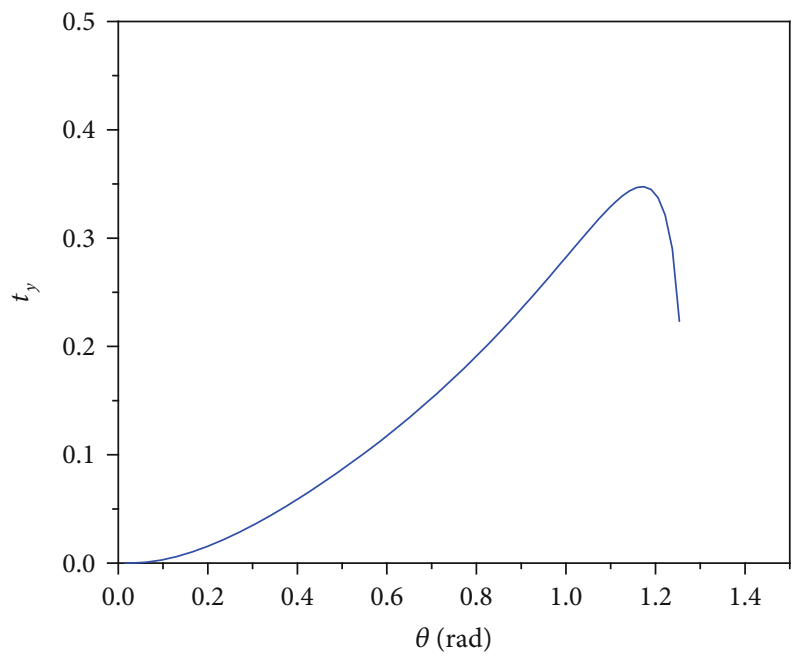

- Thickness of wear at $y$-axis

(c) $\Phi_{1}=111.6 \mathrm{~mm}, \Phi_{2}=98 \mathrm{~mm}$

Figure 10: $\Phi_{1}, \Phi_{2}, \theta$, and wear relationship.

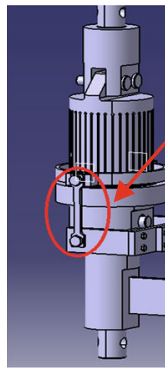

(a) Assembly drawing

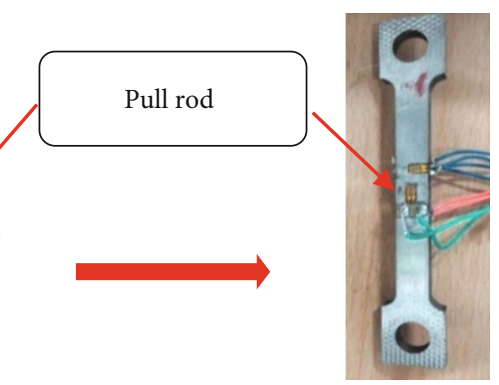

(b) Test article

FIGURE 11: The pull rod strain gauge in the experiment. (a) Assembly drawing. (b) Test article.

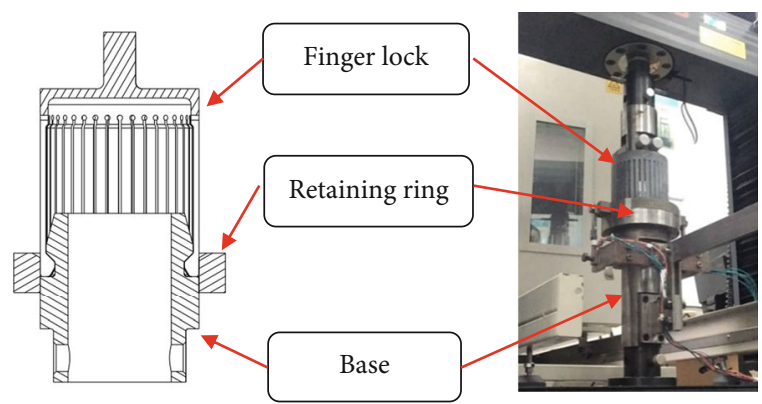

(a) CAD assembly

FIgURE 12: Assembly scheme of the finger lock. (a) CAD assembly. (b) Test article. 


Figure 13: The finger lo

TABLe 3: Axial preload of finger locks.

\begin{tabular}{lllllllllllllllll}
\hline Number & 1 & 2 & 3 & 4 & 5 & 6 & 7 & 8 & 9 & 10 & 11 & 12 & 13 & 14 & 15 & 16 \\
\hline $\begin{array}{l}\text { Force } \\
(\mathrm{kN})\end{array}$ & 1 & 1.5 & 2 & 3 & 4 & 5 & 6 & 7 & 8 & 9 & 10 & 12 & 14 & 16 & 18 & 20 \\
\hline
\end{tabular}

adhesion wear, fatigue wear, and so on. According to the actual situation, the main wear forms of the finger lock are abrasive wear and adhesive wear. They have a common basic contact hypothesis: the wear of contact body is related to their material properties, normal pressure of wear surface, and wear distance. The following is its constitutive equation:

$$
V=\frac{K N_{V}}{H} l
$$

In equation (20), $V$ is the wear volume, $K$ is the wear coefficient, $N_{V}$ is the normal contact force, $l$ is the sliding distance, and $H$ is the hardness coefficient.

The differential equations of the Archard model can be obtained by differential equations on both sides of the equation:

$$
d V=\frac{K N_{V}}{H} d l
$$

According to Figure 6, in the finger lock, $l$ is the length of edge $A C$ :

$$
l=b .
$$

Taking equation (22) into equation (21), it can be obtained as

$$
d V=\frac{K N_{V}}{H} d b .
$$

According to the geometric relationship of the finger lock in Figure 6, it can be obtained as

$$
\begin{aligned}
& \sin \beta=\frac{h}{a}, \\
& \frac{\sin \beta}{b}=\frac{\sin \gamma}{c} .
\end{aligned}
$$

Solving equations (13), (24), and(25), $b$ can be obtained as

$$
b=\frac{h c}{a \sin \gamma}=a \cos \gamma+\sqrt{c^{2}-a^{2} \sin ^{2} \gamma} .
$$

Taking the differential between the two sides of equation (26), it can be obtained as

$$
d b=\frac{c d c}{\sqrt{c^{2}-a^{2} \sin ^{2} \gamma}} .
$$

Then, taking equations (18) and (27) into equation (23), it can be obtained as

$$
\begin{aligned}
d V & =\frac{3 K E I\left(a \sin \gamma \cos \gamma+\sqrt{c^{2} \sin ^{2} \gamma-a^{2} \sin ^{4} \gamma}\right)}{\cos \alpha H c^{2} \sqrt{c^{2}-a^{2} \sin ^{2} \gamma}} d c \\
& =\frac{3 K E I\left(-a \sin \theta \cos \theta+\sqrt{c^{2} \sin ^{2} \theta-a^{2} \sin ^{4} \theta}\right)}{\cos \alpha H c^{2} \sqrt{c^{2}-a^{2} \sin ^{2} \theta}} d c .
\end{aligned}
$$

In equation (28), $E$ is Young's modulus of the finger lock and $I$ is the moment of inertia of the finger lock.

As shown in Figure 9, according to the initial geometric parameters, the value range of $c$ is $117 \mathrm{~mm}$ to $125 \mathrm{~mm}$. The angles of $\theta$ are $30^{\circ}, 45^{\circ}$, and $60^{\circ}$, respectively. It can be observed that in this range, the change rate of the original function curve is small. 


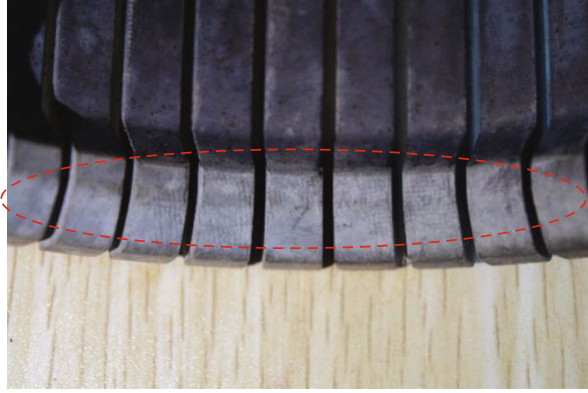

(a) Type 001 unworn

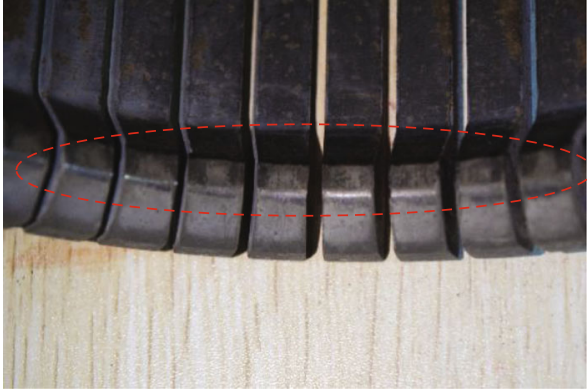

(b) Type 001 worn

FIGURE 14: Real object comparison of type 001 between unworn and worn.

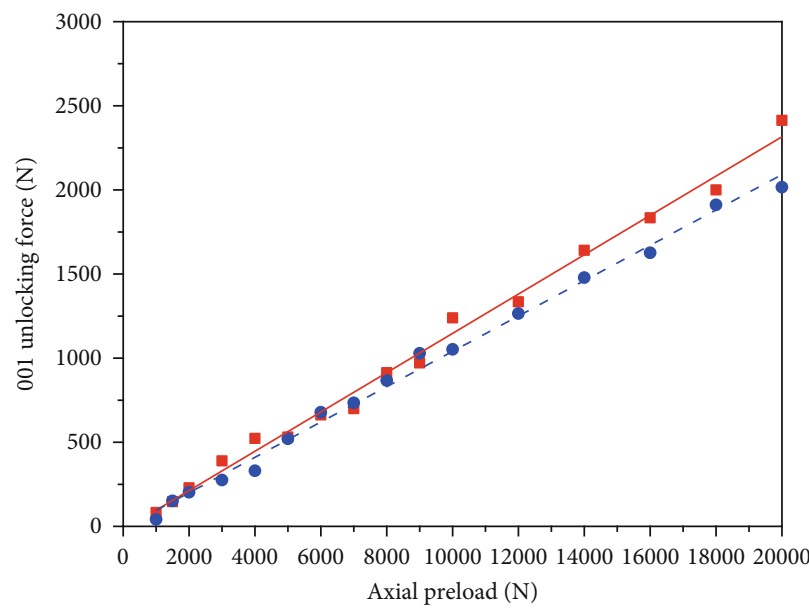

- Experimental unworn - Linear fit of experimental unworn - Experimental worn - - - Linear fit of experimental worn

01

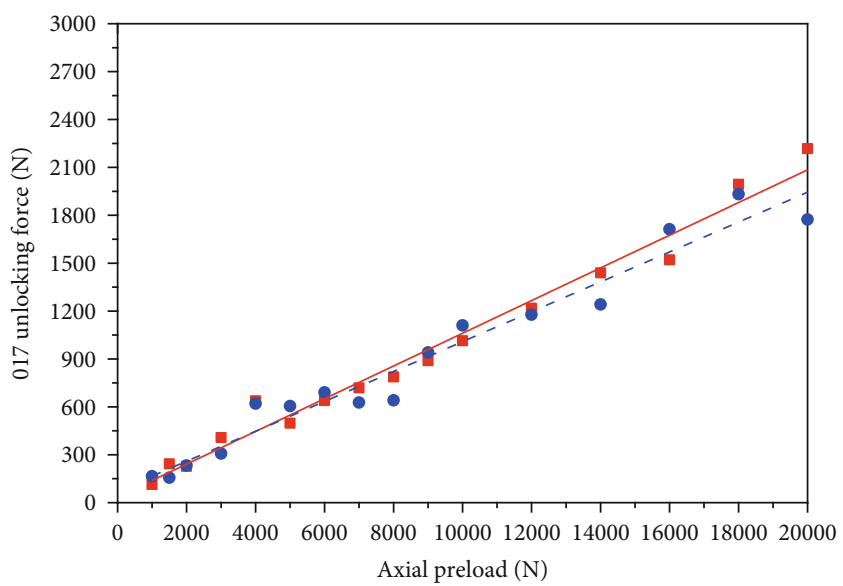

- Experimental unworn

- Experimental worn
- Linear fit of experimental unworn - - - Linear fit of experimental worn 017

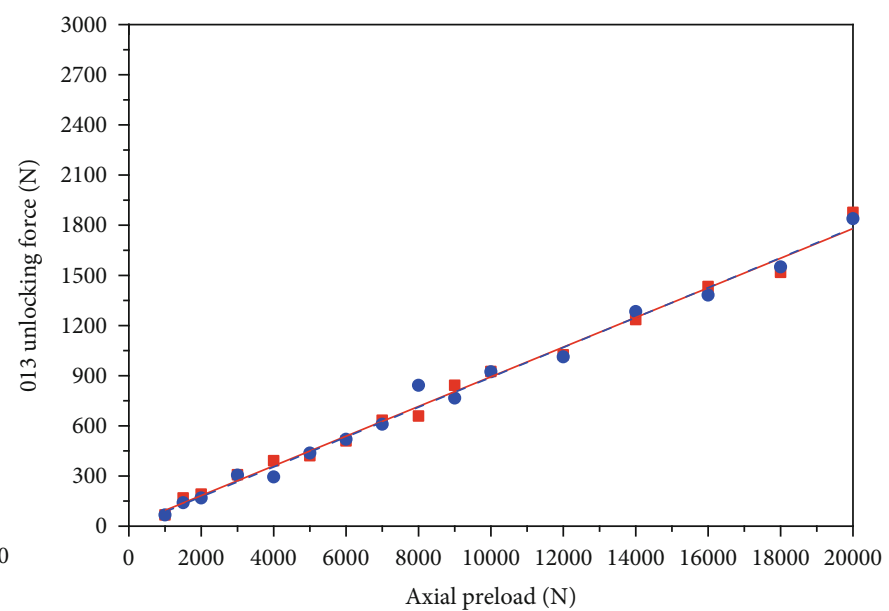

- Experimental unworn

- Experimental worn

- Linear fit of experimental unwor - - - Linear fit of experimental worn

013

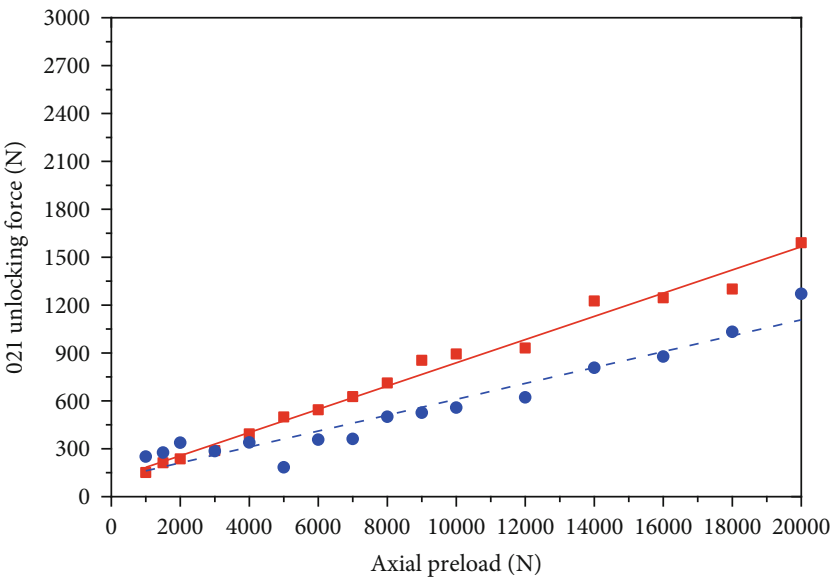

- Experimental unworn

- Experimental worn - - - Linear fit of experimental worn 021

FIGURE 15: Various types of finger lock unlocking force and axial preload relationship. 

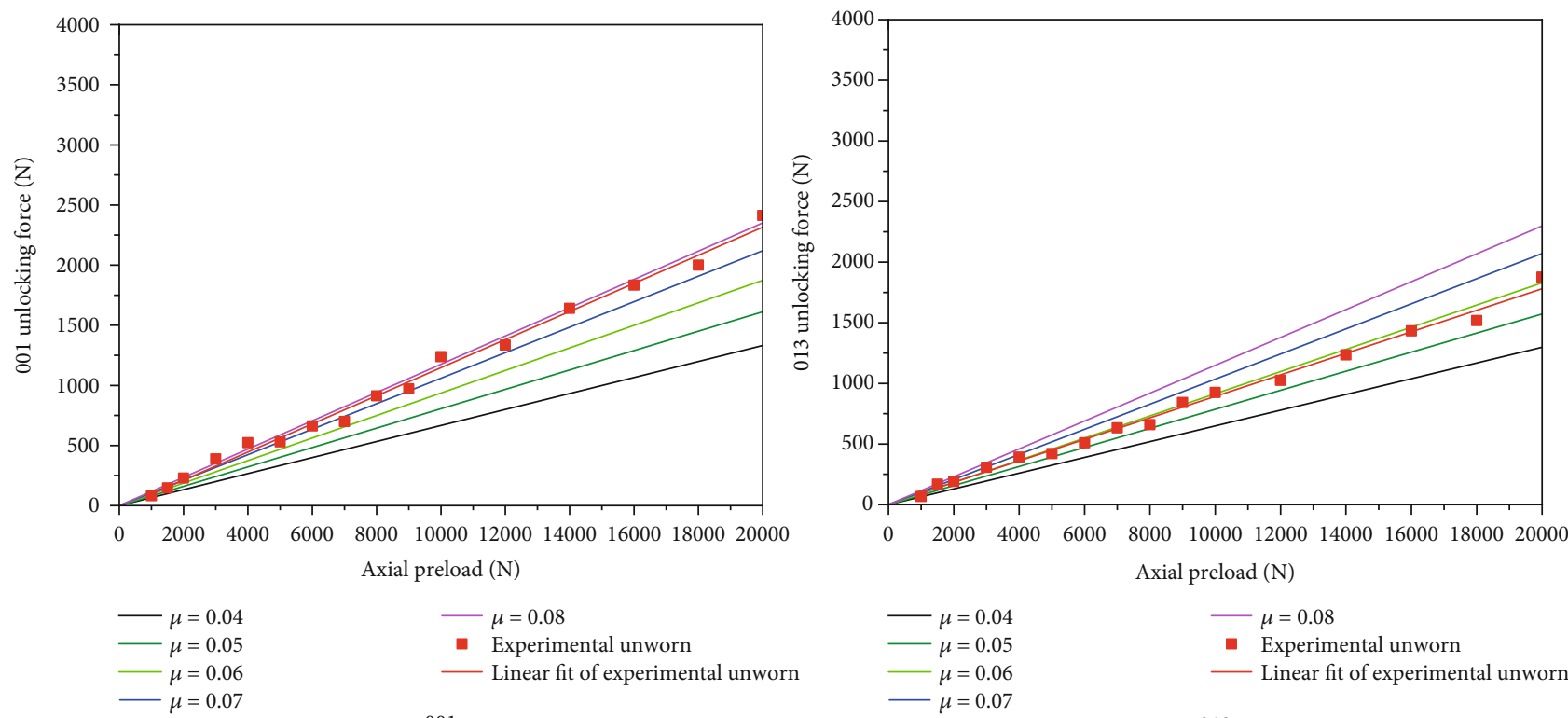

$-\mu=0.08$

- Experimental unworn

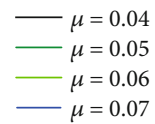

001
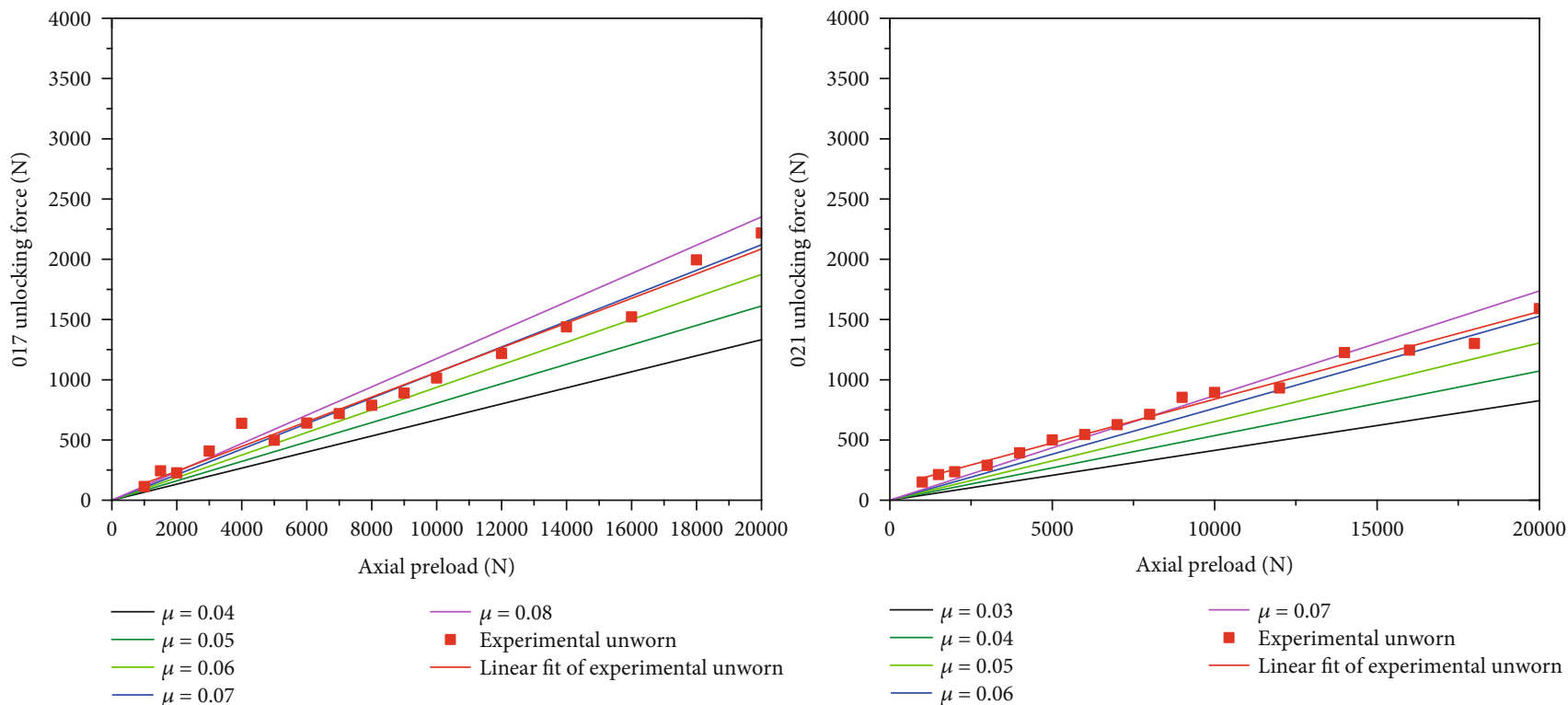

017

021

FIGURE 16: Friction coefficient curve of each finger lock with unworn.

By integrating the equation (28), the value of $V$ can be obtained as

$$
\begin{aligned}
V & =\int_{c 0}^{c 1} \frac{3 K E I\left(a \sin \gamma \cos \gamma+\sqrt{c^{2} \sin ^{2} \gamma-a^{2} \sin ^{4} \gamma}\right)}{\cos \alpha H c^{2} \sqrt{c^{2}-a^{2} \sin ^{2} \gamma}} d c, \\
& =\int_{c 0}^{c 1} \frac{3 K E I\left(-a \sin \theta \cos \theta+\sqrt{c^{2} \sin ^{2} \theta-a^{2} \sin ^{4} \theta}\right)}{\cos \alpha H c^{2} \sqrt{c^{2}-a^{2} \sin ^{2} \theta}} d c .
\end{aligned}
$$

In equation (29), $c 0$ and $c 1$ are the longest and shortest lengths of $c$ in Figure 6, respectively. According to the geometric relationship, it can be obtained as

$$
\begin{aligned}
& c 0=a, \\
& c 1=a+\frac{\Phi_{1}-\Phi_{2}}{\sin \theta} \cos \alpha .
\end{aligned}
$$

By calculating the area under the curve in Figure 9, the numerical solution of $V$ can be obtained.

By observing Figure 4, it can be known that the corresponding surface of edge $B C$ is worn. It is assumed that the surface area is $S_{B C}$. The thickness of the wear can be calculated as

$$
t=n \frac{V}{S_{B C}}=\frac{n}{S_{B C}} \int_{c 0}^{c 1} \frac{3 K E I\left(-a \sin \theta \cos \theta+\sqrt{c^{2} \sin ^{2} \theta-a^{2} \sin ^{4} \theta}\right)}{\cos \alpha H c^{2} \sqrt{c^{2}-a^{2} \sin ^{2} \theta}} d c .
$$




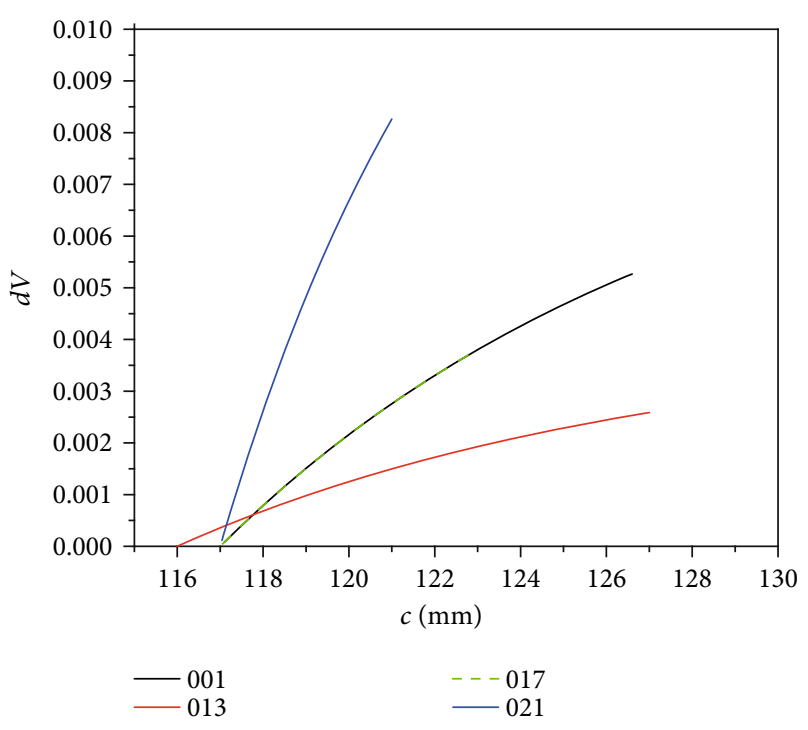

Figure 17: Wear integral curve of different finger locks.

TABLE 4: Theoretical calculation results of wear thickness of each finger lock.

\begin{tabular}{lcc}
\hline Model & Wear volume $V\left(\mathrm{~mm}^{3}\right)$ & Wear thickness $t_{y}(\mathrm{~mm})$ \\
\hline 001 & 25.0 & 0.19 \\
013 & 14.0 & 0.20 \\
017 & 10.5 & 0.16 \\
021 & 17.0 & 0.31 \\
\hline
\end{tabular}

In equation (31), $n$ is the cycle of wear. The $S_{B C}$ and $I$ are

$$
\begin{aligned}
S_{B C} & =L_{B C} \cdot L_{B C z}=\frac{\left(\Phi_{1}-\Phi_{2}\right)}{\sin \theta}\left(\frac{\Phi \pi}{36}-2\right), \\
I & =\frac{((\Phi \pi / 36)-2)\left(\Phi-\Phi_{1}\right)}{12} .
\end{aligned}
$$

Therefore, the thickness variation caused by wear in $Y$ direction is

$t_{y}=t \cdot \sin \theta=\frac{n K E\left(\Phi-\Phi_{1}\right) \sin ^{2} \theta}{4 H\left(\Phi_{1}-\Phi_{2}\right)} \int_{c 0}^{c 1} \frac{-a \sin \theta \cos \theta+\sqrt{c^{2} \sin ^{2} \theta-a^{2} \sin ^{4} \theta}}{\cos \alpha c^{2} \sqrt{c^{2}-a^{2} \sin ^{2} \theta}} d c$.

It can be observed from Figure 9 that the derivative of the curve of wear volume changes little within the value range. Therefore, the approximate solution of $t_{y}$ can be approximately calculated as the area of triangle under the curve:

$$
\begin{aligned}
t_{y} \approx & \frac{n K E\left(\Phi-\Phi_{1}\right) \sin \theta}{8 H} \\
& \cdot \frac{\sqrt{\left(a+\left(\left(\Phi_{1}-\Phi_{2}\right) / \sin \theta\right) \cos \alpha\right)^{2} \sin ^{2} \theta-a^{2} \sin ^{4} \theta}-a \sin \theta \cos \theta}{\left(a+\left(\left(\Phi_{1}-\Phi_{2}\right) / \sin \theta\right) \cos \alpha\right)^{2} \sqrt{\left(a+\left(\left(\Phi_{1}-\Phi_{2}\right) / \sin \theta\right) \cos \alpha\right)^{2}-a^{2} \sin ^{2} \theta}} .
\end{aligned}
$$

The relationship among $\Phi_{1}, \Phi_{2}, \theta$, and wear is shown in Figure 10. It can be observed from Figure 10 that within the value range of $109 \mathrm{~mm} \sim 115 \mathrm{~mm}, t_{y}$ increases with the increase of $\Phi_{1}$, so they are positively related and the change rate is small. In the range of $98 \mathrm{~mm} \sim 102 \mathrm{~mm}, t_{y}$ decreases with the increase of $\Phi_{2}$, so they are negatively correlated with a small rate of change. In the range of $0^{\circ} \sim 90^{\circ}, t_{y}$ first increases with $\theta$ , reaches the maximum near $70^{\circ}$, then decreases, and the change rate is large.

\section{Wear Calculation Model for Calibrating Finger Lock in Experiment}

3.1. Introduction of Experimental System. The experiment of finger lock was carried out on the SANS electric tension and compression tester. After preloading, the retaining ring is pulled down through the pull rod to unlock. The unlocking force under preload can be obtained by measuring the strain of pull rod. Strain gauge arrangement of pull rod is shown in Figure 11

In the experiment, the assembly drawing of the finger lock is shown in Figure 12.

As shown in Figure 13, in the experiment, four types of finger locks were tested $[23,24]$. The specific design parameters of the finger lock are shown in Table 2. For these four finger locks, 001 is the reference parameter finger lock, and the other three finger locks change one design parameter, respectively.

This experiment consists of three parts: (1) fixed preload unlocking experiment with no wear, (2) one complete working cycle experiment (500 unlocking cycles), and (3) fixed preload unlocking experiment after wear.

(1) Fixed preload unlocking experiment with no wear: as shown in Figure 12, the base was fixed, after the finger lock was sleeved into the base, the retaining ring was sleeved on the outside of the finger lock. Firstly, the loading device was controlled to apply the axial tension $P$ of the finger lock (the different axial preload in the experiment are shown in Table 3 ). Because of the existence of retaining ring, the finger lock had no axial displacement. Then, applied a vertical downward unlocking force to the retaining ring. After the retaining ring moves for $10 \mathrm{~mm}$, the unlocking process was completed.

(2) One complete work cycle experiment: pulled down the retaining ring, then controlled the loading device to move the finger lock upward for $40 \mathrm{~mm}$, and then returned the original path to the starting position of $0 \mathrm{~mm}$, which meant one unlocking cycle was completed. For the whole process, the rising process was the unlocking process, and the return process was the locking process. This process was repeated 500 times.

(3) Fixed preload unlocking experiment after wear: after 500 unlocking cycle experiments of the finger lock, the debris on the surface of the test piece and fixture 

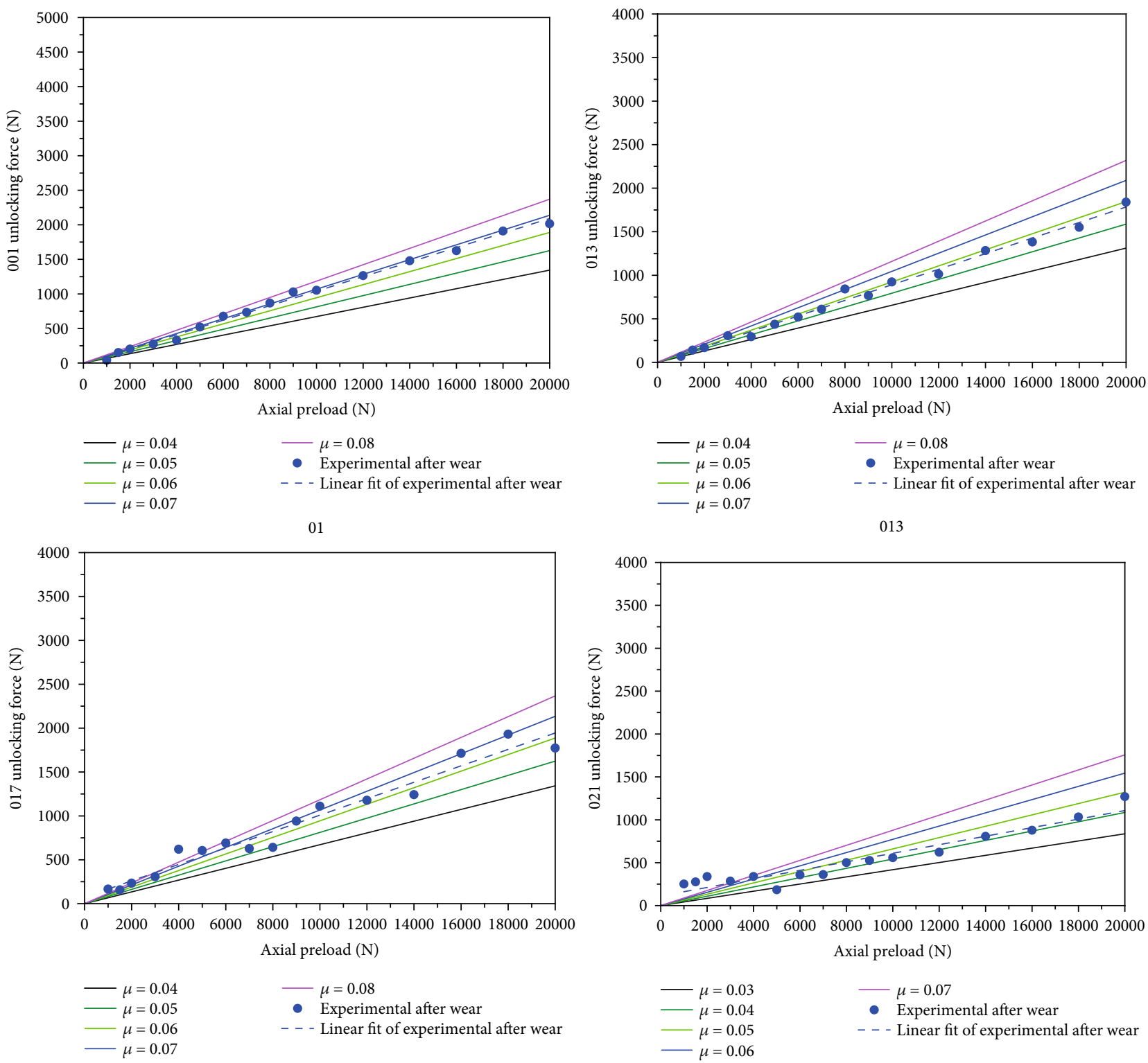

017

021

Figure 18: Friction coefficient curve of each finger lock after worn.

TABle 5: The change of friction coefficient of the finger lock in experiment.

\begin{tabular}{lcc}
\hline Model & $\begin{array}{c}\text { Friction coefficient with } \\
\text { unworn }\end{array}$ & $\begin{array}{c}\text { Friction coefficient after } \\
\text { wear }\end{array}$ \\
\hline 001 & 0.08 & 0.07 \\
013 & 0.06 & 0.06 \\
017 & 0.07 & 0.06 \\
021 & 0.05 & 0.04 \\
\hline
\end{tabular}

was cleaned. The fixed preload unlocking experiment according to (1) was repeated.

3.2. Experimental Result. As shown in Figure 14, it is the test article comparison of 001 finger lock before and after wear. It could be observed from the surface of the finger lock that after 500 unlocking cycles, the convex part of the finger lock presents a small wear mark which is horizontal to the direction of movement. The surface of the wear was brighter, and the brighter the area was, the more serious the wear was. It could be observed from Figure 14 that the upper and lower chamfers of the finger lock bulge showed obvious brightness, with obvious boundary compared with other positions, and the plane between the upper and lower chamfers had obvious scratches.

As shown in Figure 15, the relationship between the unlocking force and axial preload of the finger lock with different design parameters can be obtained. The abscissa is the finger lock axial preload and the ordinate is the finger lock unlocking force corresponding to preload, in which tensile force is positive and compression force is negative. The finger 


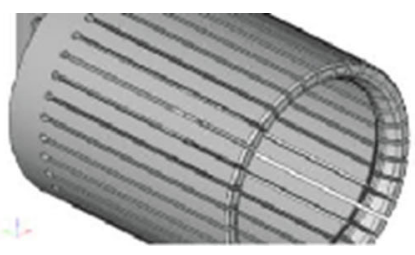

(a) Mesh of a finger lock

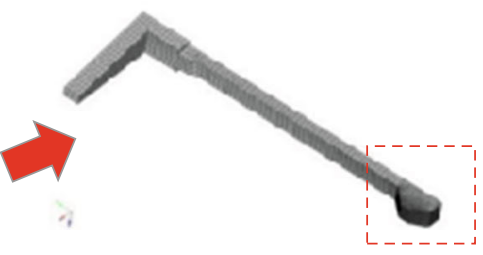

(b) Mesh of a single contact finger

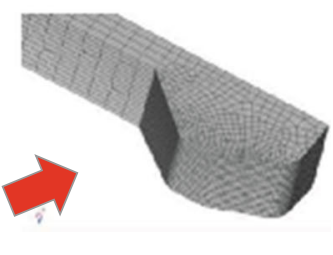

(c) Mesh of a finger lock bulge

Figure 19: Mesh of the finger lock. (a) Mesh of a finger lock. (b) Mesh of a single contact finger. (c) Mesh of a finger lock bulge.

TABLE 6: 40CrNi2Si2MoVA mechanical properties parameters.

\begin{tabular}{lccc}
\hline Material & $\begin{array}{c}\text { Elastic modulus } \\
(\mathrm{GPa})\end{array}$ & $\begin{array}{c}\text { Poisson's } \\
\text { ratio }\end{array}$ & Hardness \\
\hline 40CrNi2Si2MoVA & 199 & 0.32 & HRC45 HRC51 \\
\hline
\end{tabular}

lock of each design parameter is made into a diagram, and each diagram has two curves, respectively: the linear fitting curve corresponding to the relationship between the preload and unlocking force when the finger lock is unworn, and the linear fitting curve corresponding to the relationship between preload and unlocking force after 500 unlocking cycles.

It can be observed from Figure 15 that the unlocking force of the four types of finger locks is basically linearly proportional to preload, and the unlocking force will increase with the increase of preload. After 500 unlocking cycles of the finger lock, the unlocking force with the same preload is smaller than that with unworn.

3.3. Parameter Calibration of Finger Lock with Unworn. In Section 2.2, the unlocking force of the finger lock is calculated theoretically, and the friction coefficient in the equation is unknown. The friction coefficient can be obtained by comparing the experimental and theoretical results of four finger locks, as shown in Figure 16.

The friction coefficients of curves are 0.04, 0.05, 0.06, 0.07 , and 0.08 , respectively, in Figure 16. The friction coefficient between the finger lock and retaining ring can be obtained by comparing the slope of experimental value and theoretical curve.

3.4. Parameter Calibration of Finger Lock after Worn. As shown in Figure 17, it is the wear volume curve of different finger locks in the experiment. The corresponding wear volume can be obtained by calculating the area under the curve, respectively. The component of wear thickness in $Y$ direction refers to the upward movement displacement in $Y$ direction after wear of type lock, which is $t_{y}$.

According to the theoretical formula, the theoretical wear thickness is calculated, as shown in Table 4.

According to the geometric relationship after wear, the unlocking force curve after wear can be calculated. The friction coefficient can be obtained by comparing the experimental and theoretical results of four finger locks after wear, as shown in Figure 18.
As shown in Figure 18, in the curve of each finger lock, the friction coefficients are 0.04, 0.05, 0.06, 0.07, and 0.08, respectively, and their curves are drawn. According to the comparison between the slope of the experimental value and the slope of the theoretical curve, after 500 unlocking cycles, the friction coefficients between the finger lock and the retaining ring become smaller, as shown in Table 5.

\section{Finite Element Model of Finger Lock}

4.1. Create the Finite Element Model. The finger lock is a solid with cylindrical symmetry, and its load and constraint are also of cylindrical symmetry. Therefore, it is reasonable to simplify the model axisymmetrically $[6,25]$. Only one of the 36 contact fingers need to be extracted for analysis. Similarly, the base is a solid with cylindrical symmetry. The simplified process of the finite element model is shown in Figure 19. In order to improve the accuracy of calculation, the chamfer geometry of the contact position between the finger lock and the base is preserved. Because the contact surface is located in the finger lock bulge, the mesh here needs to be more dense in order to improve results' accuracy.

The software used is MSC Marc [26]. According to the experimental requirements and relevant references, the wear coefficient is set $K=10^{-4}$. The material property of $40 \mathrm{CrNi2}$ Si2MoVA is set according to Table 6.

The subroutine of Marc is written in Fortran. The subroutine used for wear simulation is called "uwearindex," and users can use a wide range of internal variable sets. According to the experimental results, a function relationship between the wear and friction coefficient is set up to simulate the change of friction coefficient during wear.

4.2. Simulation Maps. After simulation, the wear map of finger lock can be obtained. In the calculation process of 500 unlocking cycles, wear gradually occurred. The wear change map of 001 finger lock in different steps is shown in Figure 20. When the finger lock is worn 200 cycles, 400 cycles, and 500 cycles, the contact surface will show different wear states, the wear steps of each position is different, and the wear severity is also different.

It can be observed from Figure 20 that the main wear position of the finger lock occurs at the convex position where the inner surface of the lower part of the finger lock contacts the base, while no obvious wear occurs at other parts of the finger lock. After wear 200 cycles, 400 cycles and 500 cycles, the wear map shows a gradual change. With the 


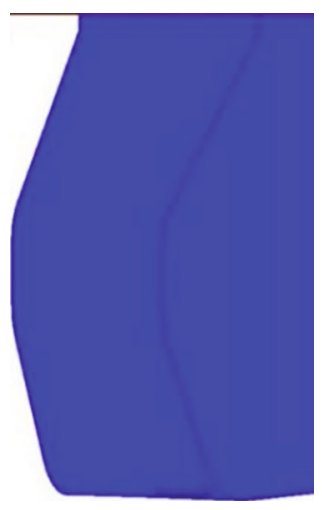

(a) Unworn

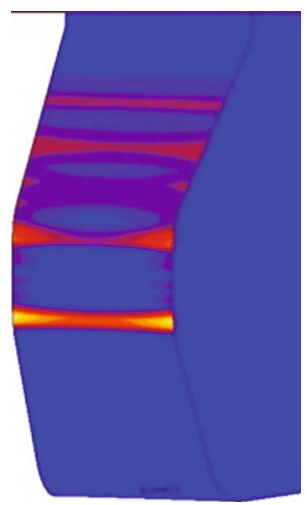

(c) Wear 400 cycles

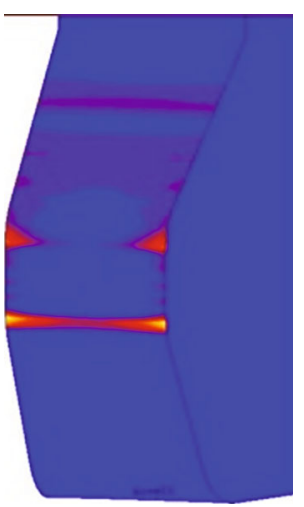

(b) Wear 200 cycles

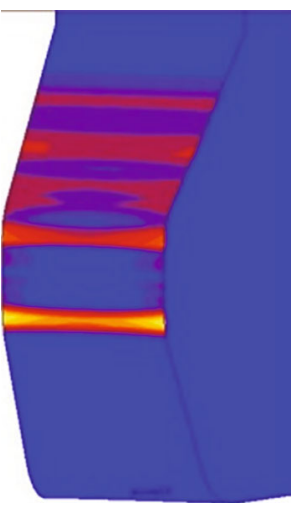

(d) Wear 500 cycles

FIgURE 20: Wear map of 001 finger lock in different steps.

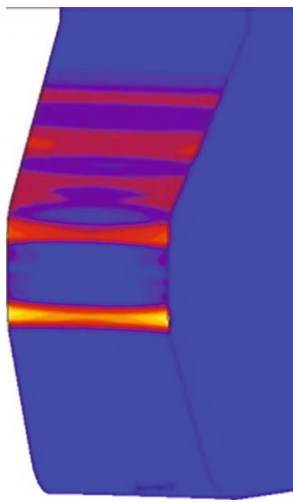

(a) Simulated wear map

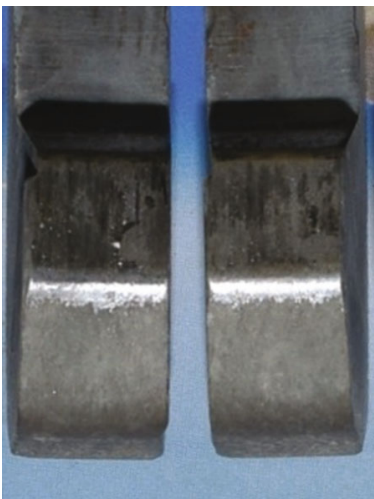

(b) Experimental wear map

FIGURE 21: Comparison of wear between the simulated surface and experimental surface of 001 .

increase of unlocking cycles, the outer edge of the contact surface will wear first, and the whole contact process is a line contact process. Finally, the maximum position of wear is located at the lower chamfer of the finger lock protrusion and the protrusion of base contact. At this position, the entire chamfer is worn. In the plane between the upper chamfer and the lower chamfer, there is partial wear on the left and right sides of the plane of the finger lock, and it presents a toothed distribution; the upper chamfer of the finger lock protrusion is another location where there is greater wear, but the wear here presents a distribution where the wear at both ends is serious and the wear in the middle is small; the upper inclined surface of the finger lock protrusion also has wear.

Comparing the experimental wear map and the simulated wear map in Figure 21, it can be found that the wear 

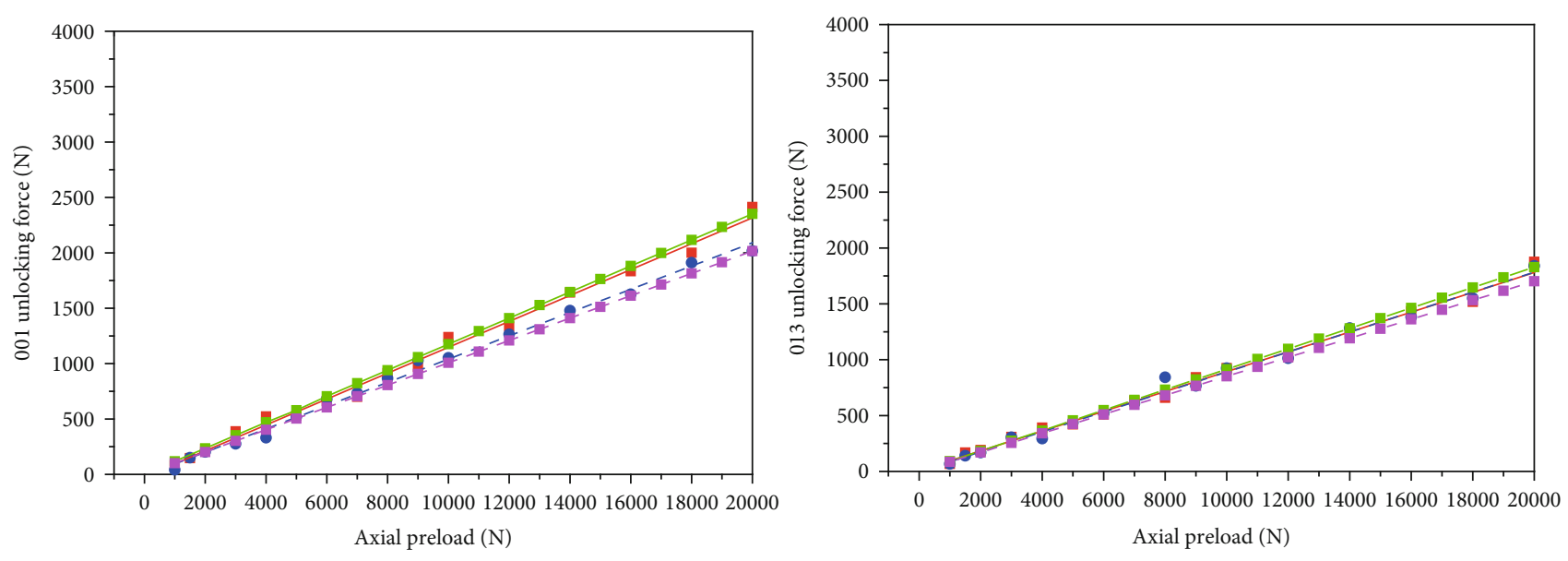

- Experimental unworn

- Experimental after wear

- Linear fit of experimental unworn

- - - Linear fit of experimental after wear

- Simulation unworn

- - Simulation after wear

001

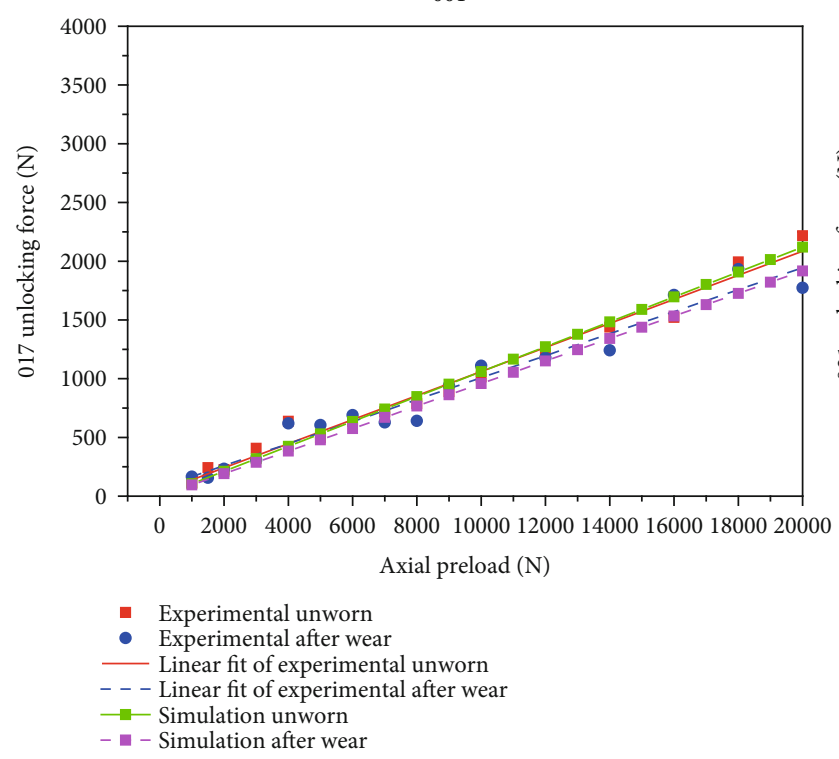

017

$$
\begin{aligned}
& \text { Experimental unworn } \\
& \text { - Experimental after wear } \\
& \text { - Linear fit of experimental unworn } \\
& - \text { - Linear fit of experimental after wear } \\
& - \text { - Simulation unworn } \\
& \text { - - Simulation after wear }
\end{aligned}
$$

013

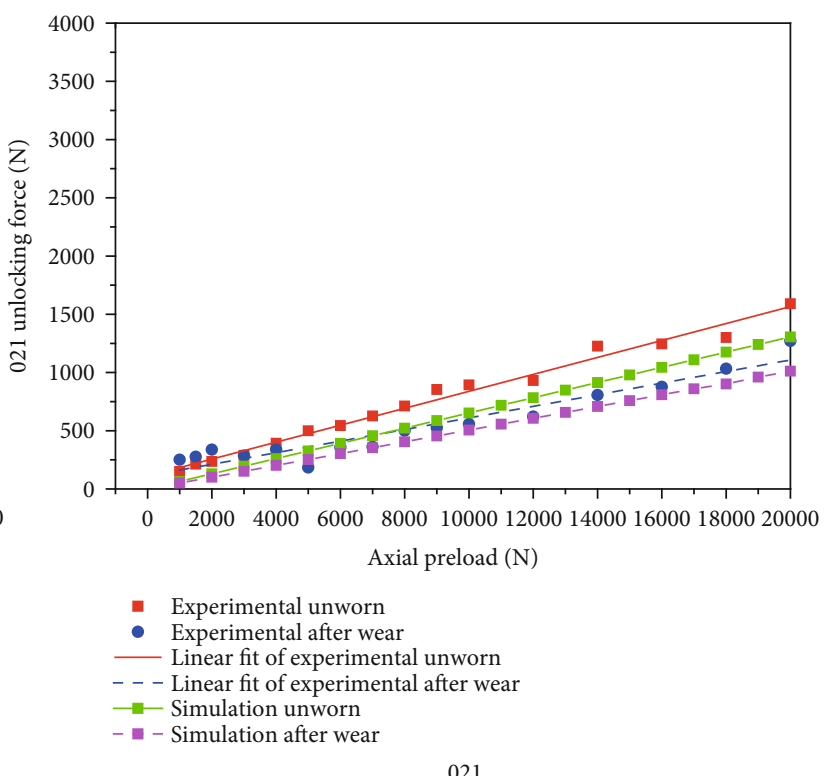

021

FIGURE 22: Various types of finger lock simulation and experiment comparison curves of unlocking force and axial preload.

position and trend of the experimental results and the simulation results are consistent, and the maximum wear position both occur at the upper and lower chamfers of the finger lock bulge.

4.3. Comparative Analysis of Experimental and Finite Element Results. The comparison between the experimental results and simulation results of the unlocking force of four types of finger locks before and after wear is shown in Figure 22. Comparing the simulation and experimental curves of four finger locks, it can be found that in the process of preloading from $1 \mathrm{kN}$ to $20 \mathrm{kN}$, the unlocking force of finger lock is basically proportional to the simulation data of axial preload, and the unlocking force of retaining ring in the simulation model will increase with the increase of axial force, and the error of simulation curve and experimental curve is not more than $10 \%$. However, the fitting degree of simulation and experimental curve of unlocking force after wear is higher before $10 \mathrm{kN}$. When it is higher than $10 \mathrm{kN}$, the simulation curve will be slightly smaller than the experimental curve with the increase of preload. This may be because wear is a nonlinear process. As the preload becomes larger, the contact changes nonlinearly, which leads to the difference between the experimental results and the simulation results. Comparing the simulation and experimental curves, it can be known that the 


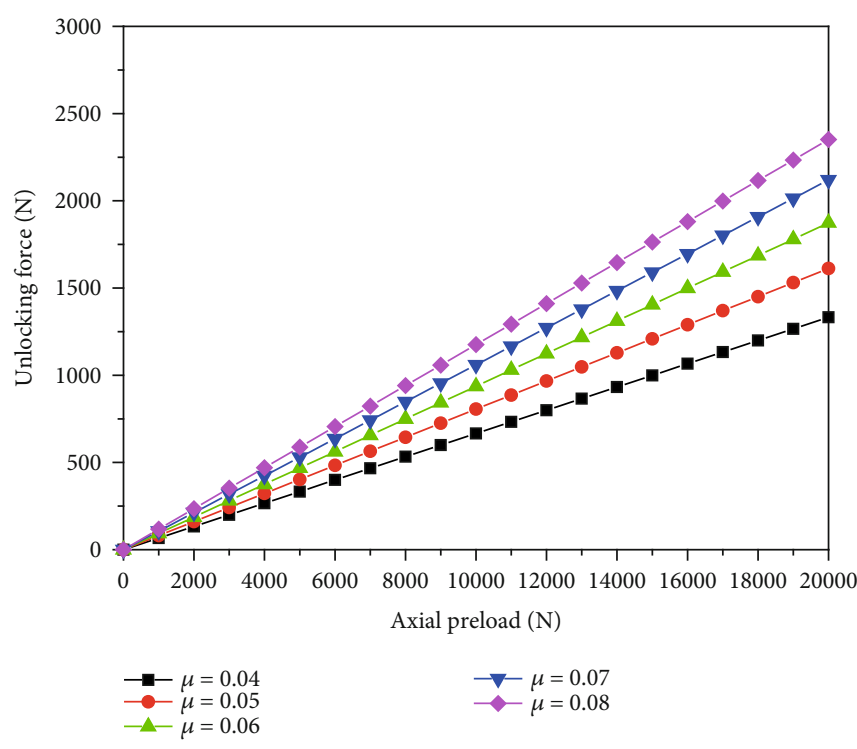

(a) $\Phi_{1}=111.6, \Phi_{2}=98$, and $\theta=45^{\circ}$

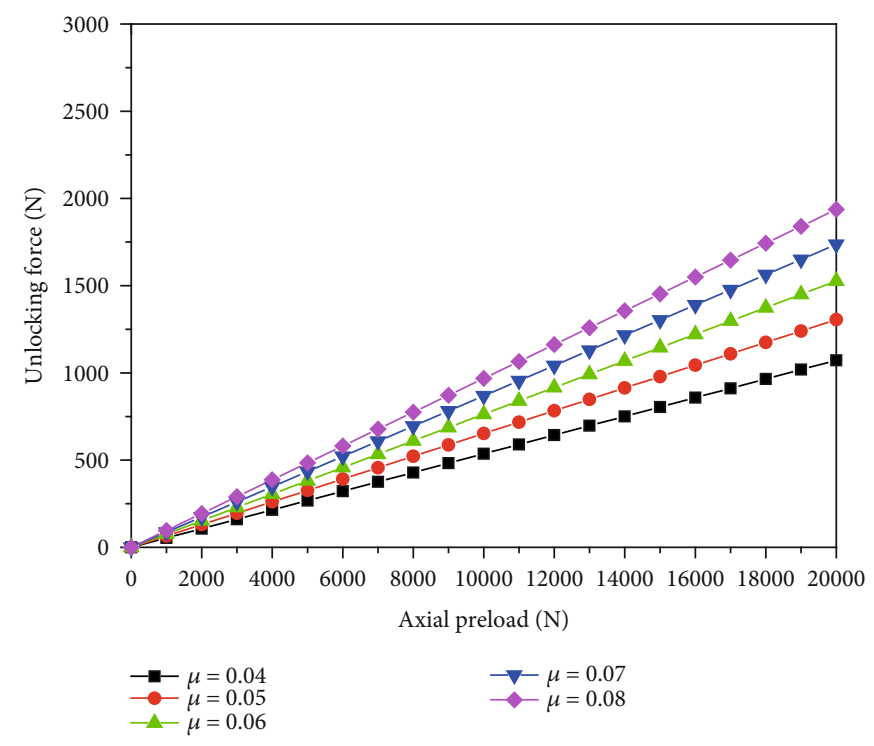

(b) $\Phi_{1}=111.6, \Phi_{2}=98$, and $\theta=60^{\circ}$

FIGURE 23: Influence of friction coefficient on unlocking force of the finger lock.

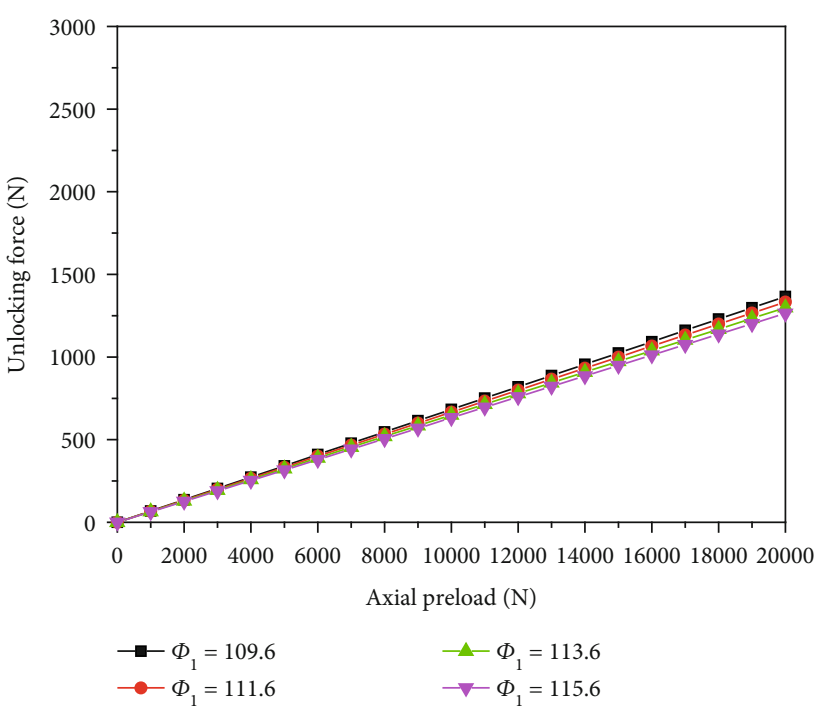

(a) $\mu=0.05, \Phi_{2}=98$, and $\theta=45^{\circ}$

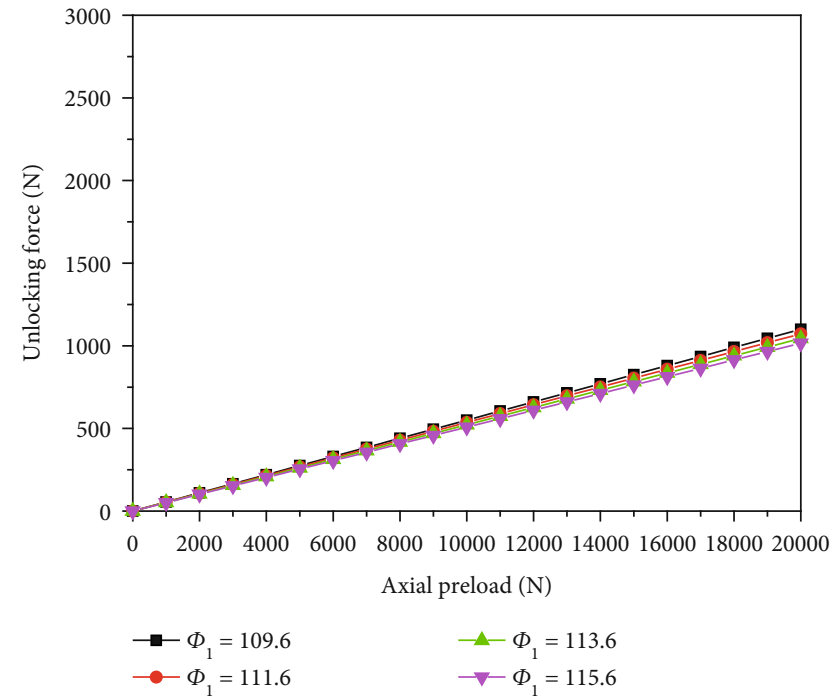

(b) $\mu=0.05, \Phi_{2}=98$, and $\theta=60^{\circ}$

FIGURE 24: Influence of $\Phi_{1}$ on unlocking force of the finger lock.

trend of simulation data and experimental data is consistent, which better reflects the mechanical behavior of finger lock unlocking force.

\section{Sensitivity Analysis of Parameters}

According to the effective finite element model of the finger lock, the finger lock models with different parameters are calculated. According to the numerical calculation results, the change rule of unlocking force and the sensitive parameters that affect the unlocking force of the finger lock are compared and analyzed.
5.1. Influence of Friction Coefficient on Unlocking Force of Finger Lock. As shown in Figure 23, friction coefficient is an important parameter affecting unlocking force. The simulation results of unlocking force and preload corresponding to different friction coefficients are shown in Figures 23(a) and 23(b) when the values of $\theta$ are $45^{\circ}$ and $60^{\circ}$. There are five curves in each figure. The values of curves are five groups of values with an interval of 0.01 , which are $0.04,0.05,0.06$, 0.07 , and 0.08 , respectively. It can be observed from Figure 23 that when the friction coefficient increases, the unlocking force of the finger lock will increase, so they are positively related, and the change of the friction coefficient has a greater impact on the unlocking force. 


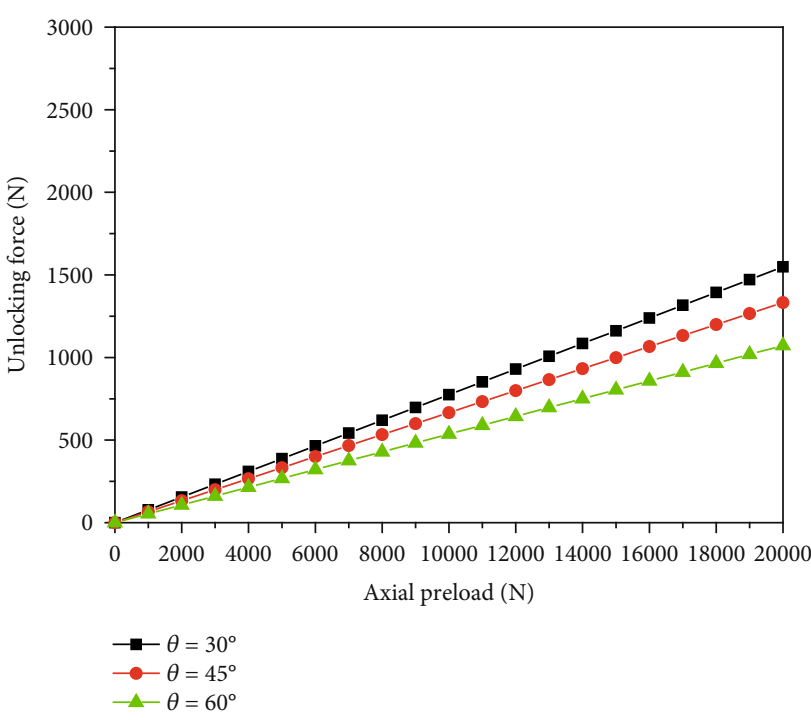

(a) $\mu=0.05, \Phi_{1}=111.6, \Phi_{2}=98$

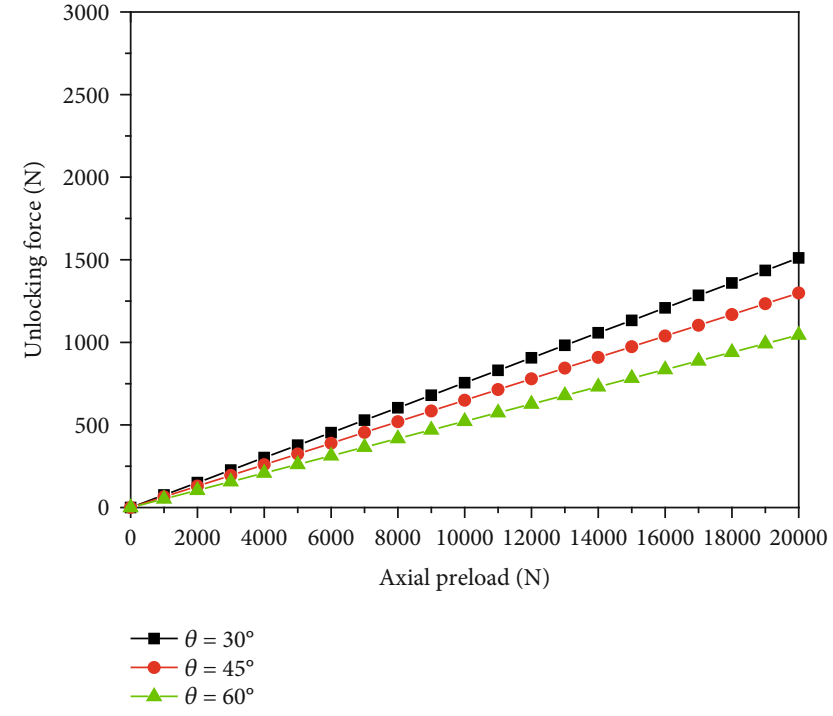

(b) $\mu=0.05, \Phi_{1}=113.6, \Phi_{2}=98$

Figure 25: Influence of fingertip angle $\theta$ on unlocking force of the finger lock.

TABle 7: Wear thickness corresponding to different $\Phi_{1}$.

\begin{tabular}{lc}
\hline$\Phi_{1}(\mathrm{~mm})$ & Wear thickness $t_{y}(\mathrm{~mm})$ \\
\hline 109.6 & 0.17 \\
111.6 & 0.19 \\
113.6 & 0.20 \\
115.6 & 0.20 \\
\hline
\end{tabular}

5.2. Influence of $\Phi_{1}$ on Unlocking Force of Finger Lock. As shown in Figure 24, diameter $\Phi_{1}$ is an important parameter affecting unlocking force. The simulation results of unlocking force and preload corresponding to different diameter $\Phi_{1}$ are shown in Figures 24(a) and 24(b) when the values of $\theta$ are $45^{\circ}$ and $60^{\circ}$. There are four curves in each figure. The values of $\Phi_{1}$ corresponding to these four curves are four groups of values with an interval of $2 \mathrm{~mm}$, which are $109.6 \mathrm{~mm}, 111.6 \mathrm{~mm}$, $113.6 \mathrm{~mm}$, and $115.6 \mathrm{~mm}$, respectively. As can be observed from Figure 24, when $\Phi_{1}$ becomes larger, the unlocking force of the finger lock will become smaller, so they are negatively related. The distance between the four curves is very small, so the change of $\Phi_{1}$ has little effect on the unlocking force.

\subsection{Influence of Fingertip Angle on Unlocking Force of Finger} Lock. As shown in Figure 25, the fingertip angle $\theta$ is an important parameter affecting the unlocking force. The simulation results of different unlocking forces and preload are shown in Figures 25(a) and 25(b) when the values of $\Phi_{1}$ are $111.6 \mathrm{~mm}$ and $113.6 \mathrm{~mm}$. There are three curves in each figure. The values of $\theta$ corresponding to these three curves are $30^{\circ} / 45^{\circ} / 60^{\circ}$. As can be observed from Figure 25, the unlocking force of the finger lock will be smaller when it is larger, so they are negatively related. The change of $\theta$ leads to the obvious change of the lock force, so the change has a great influence on the unlocking force.

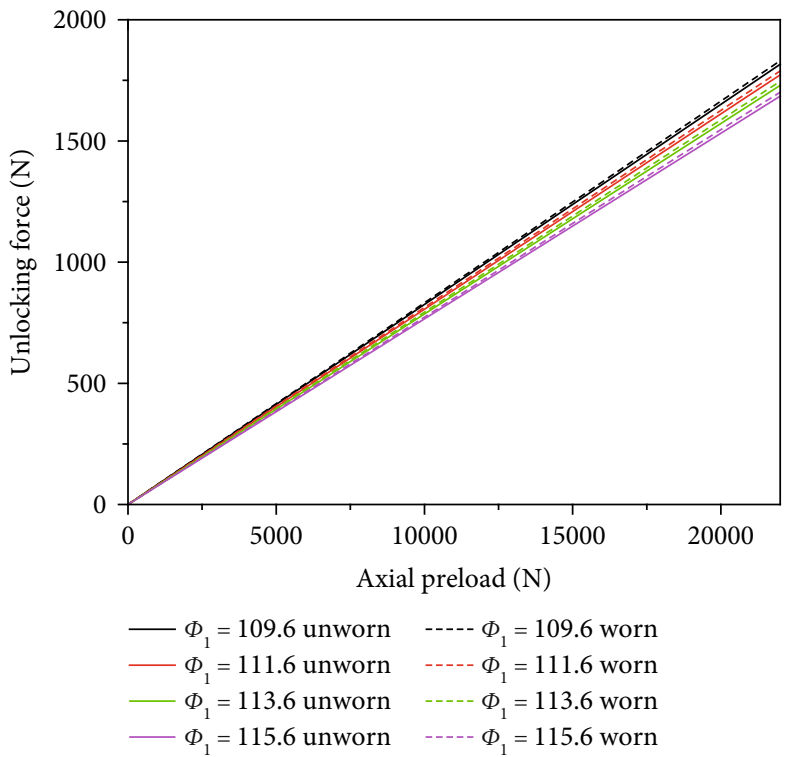

FIgURE 26: Unlocking force corresponding to different $\Phi_{1}$, and $\mu$ $=0.05, \theta=45^{\circ}$, and $\Phi_{2}=98$.

5.4. Influence of Wear on Unlocking Force of Finger Lock. After 500 unlocking cycles, the length of edge $B C$ of the finger lock in $Y$ direction will be reduced due to wear. This wear thickness is the direct influence factor of wear on unlocking force, and $\Phi_{1}, \Phi_{2}$, and $\theta$ will affect the wear.

As shown in Table 7 , when $\mu=0.05, \theta=45^{\circ}$, and $\Phi_{2}=98$, the wear thickness in $Y$ direction of edge $B C$ corresponding to different $\Phi_{1}$ can be obtained. The larger $\Phi_{1}$ is, the greater the wear thickness is. Therefore, $\Phi_{1}$ is positively related to the wear thickness. By observing Figure 26, it can be known from the simulation calculation that when the $\Phi_{1}$ of the finger lock is the same, the worn curve is above the unworn curve, so the wear will cause the unlocking force to increase. However, it 
TABLE 8: Wear thickness corresponding to different $\theta$.

\begin{tabular}{lc}
\hline$\theta\left(^{\circ}\right)$ & Wear thickness $t_{y}(\mathrm{~mm})$ \\
\hline 30 & 0.09 \\
45 & 0.19 \\
60 & 0.31 \\
\hline
\end{tabular}

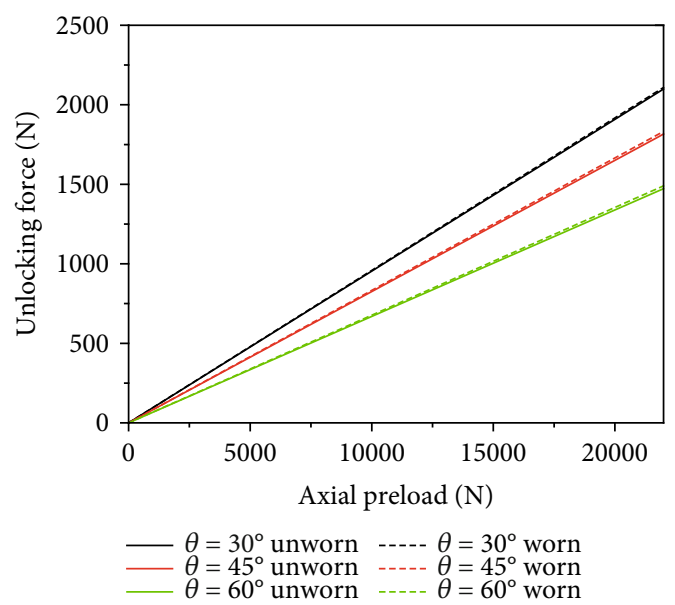

FIGURE 27: Unlocking force corresponding to different $\theta$ and $\mu=$ $0.05, \Phi_{1}=111.6$, and $\Phi_{2}=98$.

TABle 9: Wear thickness corresponding to different $\Phi_{2}$.

\begin{tabular}{lc}
\hline$\Phi_{2}(\mathrm{~mm})$ & Wear thickness $t_{y}(\mathrm{~mm})$ \\
\hline 94 & 0.21 \\
98 & 0.19 \\
102 & 0.15 \\
106 & 0.10 \\
\hline
\end{tabular}

can be observed from Figure 26 that the curve separation before and after wear is very small, so the impact of wear on the unlocking force of the finger lock is small.

As shown in Table 8, when $\mu=0.05, \Phi_{1}=111.6$, and $\Phi_{2}=98$, the wear thickness of edge $B C$ corresponding to different $\theta$ in $Y$ direction can be obtained. The greater the $\theta$ is, the greater the wear thickness is. $\theta$ is positively related to wear thickness. By observing Figure 27, it can be known from the simulation calculation that when the finger locks are the same, the worn curve is above the unworn curve, so the wear will cause the unlocking force to increase. It can be observed from the figure that the curve separation before and after wear is very small, so the impact of wear on the unlocking force of finger lock is small.

As shown in Table 9, when $\mu=0.05, \theta=45^{\circ}$, and $\Phi_{1}=$ 111.6, the wear thickness of edge $B C$ corresponding to different $\Phi_{2}$ in $Y$ direction can be obtained. The larger $\Phi_{2}$ is, the smaller the wear thickness is. Therefore, $\Phi_{2}$ is negatively related to the wear thickness. By observing Figure 28, it can be known from the simulation calculation that when the $\Phi_{2}$ of the finger lock is the same, the worn curve is above the

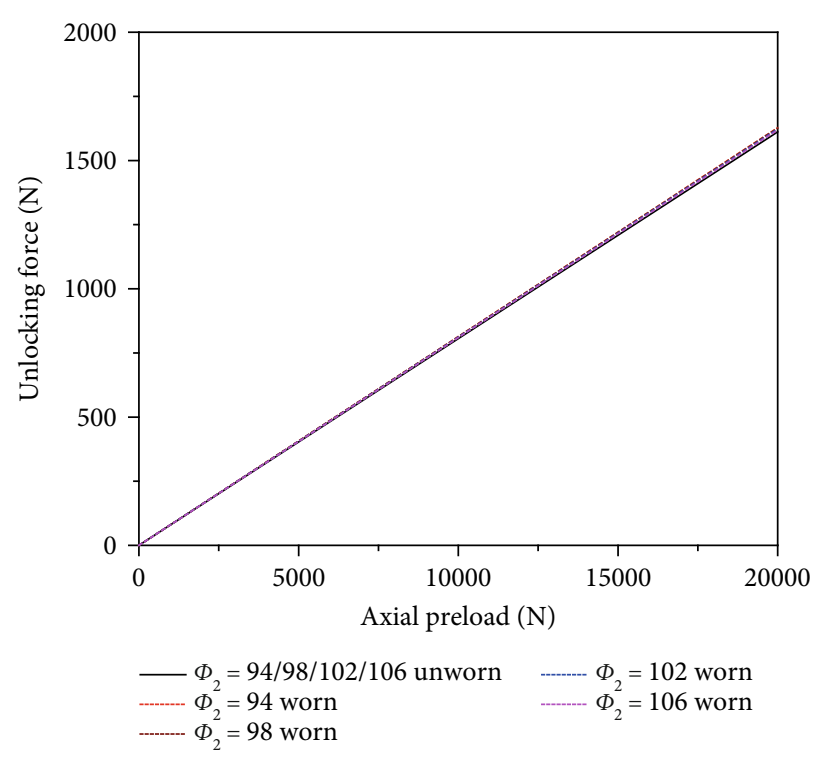

FIGURE 28: Unlocking force corresponding to different $\Phi_{2}$ and $\mu$ $=0.05, \theta=45^{\circ}$, and $\Phi_{1}=111.6$.

unworn curve, so the wear will cause the unlocking force to increase. It can be observed from the figure that the curve separation before and after wear is very small, so the impact of wear on the unlocking force of finger lock is small.

In a word, combining the curves before and after wear in Figures 26-28, it can be known that wear will lead to a larger unlocking force, and the separation between the curve after worn and the curve with unworn is very small, so wear has little impact on the unlocking force of the finger lock after 500 unlocking cycles.

\section{Conclusions}

The relationship between the preload and the unlocking force of the finger lock in the landing gear actuator (different design parameters: finger lock $\Phi_{1}, \Phi_{2}$, and $\theta$ ) is studied in this paper. Through theoretical calculation, experimental verification, and finite element simulation, the following conclusions can be drawn:

(1) During one complete working cycle (500 unlocking cycles), the contact surface of the finger lock is worn. The friction coefficient of the contact surface is changed due to wear, and the friction coefficient of the finger lock will decrease with the increase of the unlocking cycles, and the unlocking force will decrease

(2) The diameter of finger lock $\Phi_{1}$ is negatively correlated with unlocking force; $\Phi_{2}$ has no effect on unlocking force; $\theta$ is negatively correlated with unlocking force; and the wear is positively correlated with unlocking force

(3) The diameter of finger lock $\Phi_{1}$ is positively correlated with wear; $\Phi_{2}$ is negatively correlated with wear; $\theta$ is positively correlated with wear at $0^{\circ} \sim 70^{\circ}$. The 
maximum wear position occurs at the lower edge of the finger lock protrusion, and the wear of the upper slope of the finger lock bulge affects the unlocking force

(4) The change of friction coefficient is the main factor that affects the unlocking force. The friction coefficient and fingertip angle $\theta$ of the finger lock are high sensitive parameters that affect the unlocking force, and they have obvious influence on the unlocking force. The diameter of the finger lock $\Phi_{1}, \Phi_{2}$, and wear are low sensitive parameters that affect the unlocking force, and the influence on the unlocking force is weak.

\section{Abbreviations}

$F_{L}: \quad$ Tensile force of retaining ring

$F_{j}: \quad$ Normal pressure of base

$f_{j}$ : Tangential static friction of base

$f_{Z}$ : Tangential dynamic friction of retaining ring

$F_{Z}$ : Normal surface pressure of retaining ring

$P: \quad$ Tensile force of finger lock

$S$ : $\quad$ Contact area of finger lock and retaining ring

$L_{A G x}$ : Length of edge $A G$ in $X$ direction

$L_{B D x}$ : Length of point $B$ to point $D$ in $X$ direction

$L_{B D y}$ : Length of point $B$ to point $D$ in $Y$ direction

$L_{B F x}$ : Length of point $B$ to point $F$ in $X$ direction

$L_{B F y}$ : Length of point $B$ to point $F$ in $Y$ direction

$L_{C E y}$ : Length of point $C$ to point $E$ in $Y$ direction

$\Phi$ : $\quad$ Outside diameter of finger lock

$\Phi_{1}$ : Internal diameter of finger lock

$\Phi_{2}$ : Diameter of fingertip

$\theta: \quad$ Angle of fingertip

$\alpha$ : Angle of point $A$

$\beta$ : $\quad$ Angle of point $B$

$\gamma$ : $\quad$ Angle of point $C$

$a: \quad$ Edge $B C$

b: $\quad$ Edge $A C$

c: $\quad$ Edge $A B$

$h_{A}$ : Deflection at point $A$

$h$ : $\quad$ Deflection at point $C$

$N$ : $\quad$ Pressure at point $A$

$N_{V}$ : Pressure perpendicular to edge $A C$ at point $A$

$E$ : Young's modulus

I: $\quad$ Moment of inertia

$V$ : Wear volume

$K$ : Wear coefficient

$H$ : Hardness coefficient

l: $\quad$ Length of edge $A C$

c0: $\quad$ Shortest lengths of $c$

c1: Longest lengths of $c$

$t$ : Thickness of the wear

$S_{B C}$ : Contact area of finger lock and base from point $B$ to point $C$

$n$ : Cycle of wear

$t_{y}: \quad$ Wear in $Y$ direction

$L_{B C}$ : Length of point $B$ to point $C$

$L_{B C z}$ : Length of point $B$ to point $C$ in $Z$ direction.

\section{Data Availability}

In this paper, the relevant experimental data and calculation results can be obtained through the author.

\section{Conflicts of Interest}

The authors declare that they have no conflicts of interest.

\section{References}

[1] N. S. Currey, Aircraft Landing Gear Design: Principles and Practices, American Institute of Aeronautics and Astronautics, 1988.

[2] F. Bagnoli, F. Dolce, M. Colavita, and M. Bernabei, "Fatigue fracture of a main landing gear swinging lever in a civil aircraft," Engineering Failure Analysis, vol. 15, no. 6, pp. 755$765,2008$.

[3] M. Mofidi and B. Prakash, "Two body abrasive wear and frictional characteristics of sealing elastomers under unidirectional lubricated sliding conditions," Tribology - Materials, Surfaces \& Interfaces, vol. 4, no. 1, pp. 26-37, 2013.

[4] E. A. Ossa, "Failure analysis of a civil aircraft landing gear," Engineering Failure Analysis, vol. 13, no. 7, pp. 1177-1183, 2006.

[5] J. J. Kauzlarich and J. A. Williams, "Archard wear and component geometry," Proceedings of the Institution of Mechanical Engineers, Part J: Journal of Engineering Tribology, vol. 215, no. 4, pp. 387-403, 2001.

[6] L. Q. Viet and J. H. Hwang, "A semi-active controller for an aircraft landing gear equipped with magnetorheological damper," Applied Mechanics and Materials, vol. 894, pp. 2933, 2019.

[7] D. Vechtel, "How future aircraft can benefit from a steerable main landing gear for crosswind operations," CEAS Aeronautical Journal, vol. 11, no. 2, pp. 417-429, 2020.

[8] Z. Wen, Z. Zhi, Z. Qidan, and X. Shiyue, "Dynamics model of carrier-based aircraft landing gears landed on dynamic deck," Chinese Journal of Aeronautics, vol. 22, no. 4, pp. 371-379, 2009.

[9] K. V. Bagrov, "Numerical simulation of planar oscillations of a landing gear leg along the longitudinal axis of an aircraft during the landing impact," Journal of Applied and Industrial Mathematics, vol. 13, no. 3, pp. 385-389, 2019.

[10] Z. Ding, H. Wu, C. Wang, and J. Ding, "Hierarchical optimization of landing performance for lander with adaptive landing gear," Chinese Journal of Mechanical Engineering, vol. 32, no. 1, 2019.

[11] C. Yunxia, G. Wenjun, and K. Rui, "Review and propositions for the sliding/impact wear behavior in a contact interface," Chinese Journal of Aeronautics, vol. 33, no. 2, pp. 391-406, 2018.

[12] W. Deng and H. Kesari, "Depth-dependent hysteresis in adhesive elastic contacts at large surface roughness," Scientific Reports, vol. 9, no. 1, article 1639, 2019.

[13] T. Sprenkle, A. Dodson, Q. McKnight et al., "Ion friction at small values of the Coulomb logarithm," Physical Review E, vol. 99, no. 5, p. 53206, 2019.

[14] J. F. Archard, "Contact and rubbing of flat surfaces," Journal of Applied Physics, vol. 24, no. 8, pp. 981-988, 1953. 
[15] I. Nowotyńska and S. Kut, "Examining the effect of the die angle on tool load and wear in the extrusion process," Journal of Materials Engineering and Performance, vol. 23, no. 4, pp. 1307-1312, 2014.

[16] T. J. Rupert and C. A. Schuh, "Sliding wear of nanocrystalline $\mathrm{Ni}-\mathrm{W}$ : structural evolution and the apparent breakdown of Archard scaling," Acta Materialia, vol. 58, no. 12, pp. 41374148, 2010.

[17] A. Alroqi and W. Wang, "Comparison of aircraft tire wear with initial wheel rotational speed," International Journal of Aviation, Aeronautics, and Aerospace, vol. 2, no. 1, 2015.

[18] Z. Ying, M. Zhang, Q. Wang, and Y.-L. Ke, "Modeling and simulation of wear for alignment mechanism of large aircraft component," Journal of Zhejiang University Engineering Science Edition, vol. 47, no. 2, pp. 209-215, 2013.

[19] Y. Wang, H. Su, J. Dai, and S. Yang, “A novel finite element method for the wear analysis of cemented carbide tool during high speed cutting Ti6Al4V process," International Journal of Advanced Manufacturing Technology, vol. 103, no. 5-8, pp. 2795-2807, 2019.

[20] S. Wang, H. Yan, C. Liu, N. Fan, X. Liu, and C. Wang, "Analysis and prediction of high: peed train wheel wear based on SIMPACK and backpropagation neural networks," Expert Systems, vol. 1, article e12417, 2019.

[21] J. M. Challen, P. L. B. Oxley, and B. S. Hockenhull, "Prediction of Archard's wear coefficient for metallic sliding friction assuming a low cycle fatigue wear mechanism," Wear, vol. 111, no. 3, pp. 275-288, 1986.

[22] Y. K. Gao, X. B. Li, Q. X. Yang, and M. Yao, "Influence of surface integrity on fatigue strength of $40 \mathrm{CrNi} 2 \mathrm{Si} 2 \mathrm{MoVA}$ steel," Materials Letters, vol. 61, no. 2, pp. 466-469, 2007.

[23] L. Cui, X.-H. Wei, Y.-W. Ding, and Y.-P. Li, “The equivalent stiffness and damping analysis of a series-wound dualchamber buffer of landing gear," Machinery Design \& Manufacture, 2019.

[24] X. Yu, X. Deng, and W. Guan, "Design of the upper position lock for an aircraft mechanism," Machine Tool \& Hydraulics, vol. 46, no. 10, pp. 109-110, 2018.

[25] X. Guo, X. Cheng, Y. Xu, J. Tao, A. Abd el-ATY, and H. Liu, "Finite element modelling and experimental investigation of the impact of filling different materials in copper tubes during 3D free bending process," Chinese Journal of Aeronautics, vol. 33, no. 2, pp. 721-729, 2020.

[26] C. S. Manurung, H. Ambarita, Y. H. P. Manurung, F. Napitupulu, and R. A. M. Napitupulu, "FEM analysis of the HAZ temperature by heat source modeling on butt-joint process using msc marc mentat," IOP Conference Series: Materials Science and Engineering, vol. 725, article 012009, 2020. 